ISSN: 0514-7336 — ISSN electrónico: 2386-3943

DOI: https://doi.org/10.14201/zephyrus202085209228

\title{
UN SINGULAR RETRATO ROMANO DEL FORUM DE FLORENTIA ILIBERRITANA (GRANADA)
}

\section{A unique Roman portrait from the forum of Florentia Iliberritana (Granada)}

\author{
María Luisa Loza Azuaga*, José Beltrán Fortes**, María Isabel Mancilla Cabello*** y Julio Miguel \\ Román Punzón**** \\ * Instituto Andaluz del Patrimonio Histórico (IAPH). Consejería de Cultura de la Junta de Andalucía. Avda. de los \\ Descubrimientos, s/n. 41004 Sevilla. Correo-e: marial.loza@juntadeandalucia.es. ID ORCID: https://orcid.org/0000- \\ 0003-2554-8219 \\ ** Dpto. de Prehistoria y Arqueología. Facultad de Geografía e Historia. Univ. de Sevilla. C/ Doña María de \\ Padilla, 1. 41004 Sevilla. Correo-e: jbeltran@us.es. ID ORCID: https://orcid.org/0000-0001-5841-4140 \\ *** Grupo Interdisciplinar de las Ciencias y Humanidades (PAI-HUM 143). Univ. de Granada Campus de Cartuja, \\ s/n.18071 Granada. Correo-e: mancillacabello@gmail.com. ID ORCID: https://orcid.org/0000-0002-8233-9125 \\ *** MEMOLab-Laboratorio de Arqueología Biocultural. Dpto. de Historia Medieval y CC. y TT. HH. Facultad de \\ Filosofia y Letras. Univ. de Granada. Campus de Cartuja.s/n.18071 Granada. Correo-e: romanp@ugr.es. ID \\ ORCID: https://orcid.org/0000-0001-6351-2511
}

Recepción: 28/01/2020; Revisión: 12/02/2020; Aceptación: 16/03/2020

Resumen: Se estudia un retrato romano descubierto en unas recientes excavaciones desarrolladas en la ciudad de Granada, en el barrio del Albaicín -c/ Gumiel, 6-; fue recuperado en un nivel de rellenos tardoantiguos que colmataban parte de una infraestructura abovedada que se relacionaría con las construcciones del foro de Florentia Iliberritana y que se localiza en un sector muy próximo. El análisis iconográfico y estilístico del retrato, así como los paralelos conservados -en bulto redondo y relieve-, apuntan a su elaboración en los inicios del reinado de Adriano. Presenta una singular iconografía, pero que se relaciona en determinados rasgos con el retrato de Adriano, en concreto con el llamado tipo Tarragona, creado durante la estancia del emperador en esa capital -122-123 d. C.-. Pudo representar a un miembro de la elite de Florentia Iliberritana en ese período, ya que es posible que estuviera erigido en el mismo foro municipal, con un carácter honorífico, amortizado en época tardoantigua.

Palabras clave: Escultura romana; iconografía; epigrafía romana; reinado de Adriano; Hispania.

Aвstract: This paper presents the study of a Roman portrait discovered in recent excavations in the Albaicín district - c/ Gumiel, 6- of Granada. The portrait was found in a level dated to the Late Antiquity as part of the fill of a vaulted infrastructure, possibly related to the forum buildings of Florentia Iliberritana, located close by. The iconographic and stylistic analyses of the portrait, as well as the known parallels -sculptures in the round or reliefs- suggest that it was made around the early Hadrian's reign. It presents a unique iconography with certain features related to Hadrian's portrait specifically known as the 'Tarragona type', created during the Emperor's stay in this capital (122-123 AD). It represents a member of the elite from that period, whose honorary portrait could have been exhibited in the Florentia Iliberritana's municipal forum, dismantled in Late Antiquity.

Key words: Roman sculpture; iconography; Roman epigraphy; Hadrian’s reign; Hispania. 


\section{Introducción}

En el marco de una intervención arqueológica preventiva desarrollada en el Carmen del Zenete ${ }^{1}$, en el barrio del Albaicín de Granada (Fig. 1), tuvo lugar el hallazgo de una cabeza en mármol, de un personaje masculino, en los rellenos del interior de una gran subestructura de época romana, descubierta también durante dichos trabajos ${ }^{2}$. La rehabilitación del citado inmueble catalogado, que fue iniciada en agosto de 2017, llevó aparejada una intensa y minuciosa actividad arqueológica mediante su excavación, estudio de paramentos y controles de movimientos de tierra y de obra. El edificio se localiza en la intersección de la c/ Gumiel de San José y la c/ Nueva de San Nicolás, con las que linda al o y al $\mathrm{N}$, respectivamente. La manzana de viviendas en la que se inserta el edificio del carmen y sus jardines está delimitada por las citadas calles y, además, al E, por la c/ María la Miel y, al s, por la c/ Aljibe del Gato. Es, pues, una zona con un enorme potencial arqueológico en la cual, desde el s. Xvi hasta nuestros días se vienen produciendo hallazgos de época romana de enorme importancia, entre los que destacan inscripciones, elementos arquitectónicos decorativos y algunas esculturas.

1 Solar ubicado en la c/ Gumiel de San José, n. ${ }^{\circ}$ 6, cuya excavación fue realizada bajo la dirección de dos de los firmantes, M. I. Mancilla y J. M. Román, a principios de 2018.

2 Una versión inicial de este estudio fue presentada en la IX Reunión Internacional de Escultura Romana en Hispania (Yecla, Murcia, 2019), destacando entonces su vinculación con el retrato de Adriano (referencia en González-Conde, 2019: 136), pero no se ha incluido finalmente en las actas; expresamos nuestro agradecimiento por las valiosas indicaciones que nos han dado, especialmente, la profesora $\mathrm{M}$. Bonanno (Univ. degli Studi di Roma Tor Vergata) y el profesor D. Ojeda (UNED), agradecimiento extensivo a los evaluadores anónimos de este artículo. Asimismo, agradecemos al director del Museo Arqueológico de Granada, I. Toro Moyano, y al personal técnico las facilidades dadas para el estudio de la escultura. El presente trabajo se hace en el marco de las actividades de investigación de los Grupos de I + D HUM 143 y HUM 402 (Plan Andaluz de Investigación), así como del Proyecto I + D + i (HAR 2017-89004-P), subvencionado por el Ministerio de Economía y Competitividad del Gobierno de Espańa y con Fondos Feder.

\section{Descubrimientos del s. XVIII}

De gran interés fueron los hallazgos del canónigo Juan de Flores y Oddouz, en la segunda mitad del s. XviII, en un solar ubicado a pocos metros de nuestro inmueble, donde se hallaron restos pertenecientes al foro romano, concretamente parte de un pavimento enlosado con grandes lajas de Sierra Elvira, pedestales con inscripciones y una escalinata, entre otros elementos. Aunque esos descubrimientos quedaron desprestigiados por las falsificaciones posteriores de Flores (por ejemplo, Barrios y Pastor, 2017), las investigaciones y excelentes estudios publicados por Sotomayor y Orfila (Sotomayor, 2008; Sotomayor y Orfila, 2004, 2006 y 2011), basados en los planos realizados por algunos colaboradores de Juan de Flores en el s. XVIII (Fig. 2), han permitido a estos autores ubicar exactamente el sitio de la intervención de Flores en el callejero actual, en el Carmen de La Concepción, junto a la c/ María la Miel (Fig. 3). De hecho, Juan de Flores también documentó parte de ese complejo de estructuras subterráneas -denominándolas 'Mina' (Fig. 4) - que se situaban bajo el foro, a lo largo de la calle María la Miel, perpendiculares a las nuestras en su trazado principal, y que debían servir tanto como elementos estructurales cuanto como galerías para recogida, evacuación y distribución de aguas. Los resultados de las excavaciones realizadas en los últimos años en el entorno de la c/ María la Miel han puesto de manifiesto la veracidad de los restos romanos allí aparecidos hace ya casi doscientos cincuenta ańos como pertenecientes al foro romano de la ciudad, frente -como se ha dicho- a las dudas que habían creado las falsificaciones de Flores (Gómez-Moreno, 1949; Orfila 2008, 2011 y 2013; Orfila y Sánchez 2012; Román, 2017). La conversión del enclave urbano como municipium se alcanza probablemente en época augústea, como así parece testimoniar la pertenencia de la mayoría de los personajes documentados a la tribus Galeria; en aquel momento el antiguo oppidum bastetano de Iliberri pasaría a conocerse como Florentia Iliberritana, municipium Florentinum Iliberritanum ( $\mathrm{CIL} \mathrm{II} 2 / 5,621)$ o municipium Florentinorum $(\mathrm{CIL} \mathrm{II} / 5,619)$. 


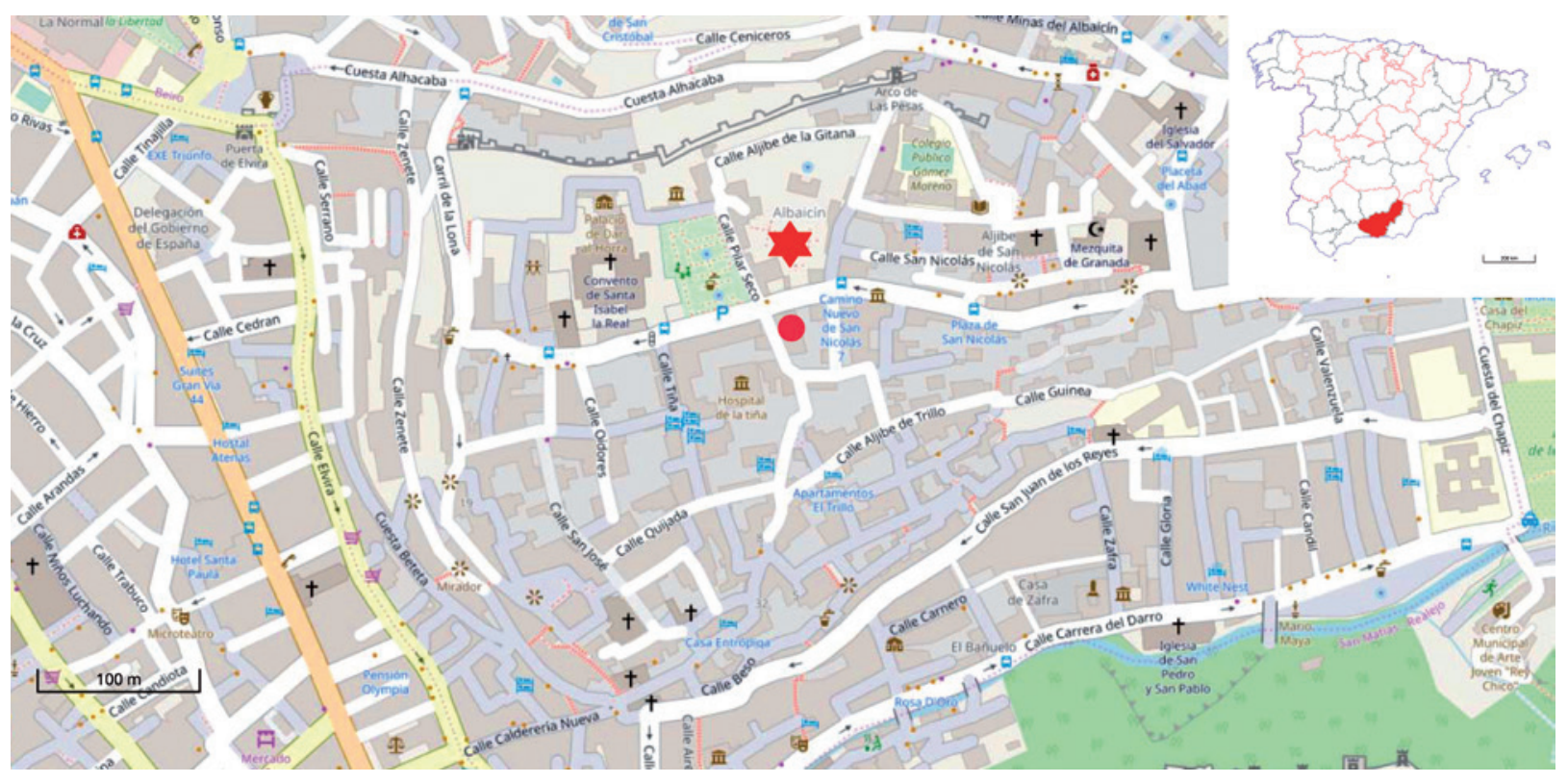

FIG. 1. Situación de la intervención arqueológica en el plano actual del barrio del Albaicín de Granada, marcado con un círculo; la estrella marca el lugar donde se localizaba el foro romano, donde se situaba el solar excavado por Juan de Flores en el s. XVIII (elaboración propia a partir del visor REDIAM, Red de información ambiental de Andalucia).

\section{Contexto arqueológico}

En nuestra intervención arqueológica se han podido identificar unas estructuras y edificios de época romana que pueden considerarse, sin lugar a duda, como excepcionales en el contexto de la arqueología de Granada y que permiten dar un soporte definitivo a la localización incuestionable de Florentia Iliberritana en esta capital. Por un lado, la imponente infraestructura subterránea, a la que nos hemos referido antes, de $3 \mathrm{~m}$ de altura x 2,5 $\mathrm{m}$ de anchura, y de la cual se han documentado varias galerías interconectadas (Fig. 5), excavadas en la roca madre hasta la altura de las paredes y con bóvedas de medio cañón de opus caementicium (Fig. 6). La galería principal ha sido documentada en unos $30 \mathrm{~m}$ de longitud, y la interpretamos, de modo preliminar, como una infraestructura relacionada, por su límite meridional, con el foro romano. Además, presenta la peculiaridad de recoger y canalizar hacia otros espacios las aguas que llegaban hasta estas infraestructuras a través de ciertas conducciones, unas de plomo y otras abovedadas insertas en la misma fábrica de opus caementicium de la subestructura. Uno de esos espacios o edificios a los que seguramente se conducía, al menos, parte de esta agua, sería el gran edificio público identificado en el solar inmediato, interpretado como unas probables termas, si bien se plantea inicialmente solo a modo de propuesta a falta de completar la intervención, aún en curso, y su posterior investigación. De este gran edificio público se han identificado tres enormes salas, una con pavimento empedrado y dos consecutivas con pavimentos de mortero y bancos adosados a sus laterales; de estas, una presenta una típica cabecera semicircular. Asimismo, el exterior de este edificio que forma su fachada meridional pudo estar decorado con varias exedras, quizás a modo de fuente-ninfeo monumental. Su estudio aún está inédito.

Centrándonos en la pieza escultórica objeto de este trabajo, fue hallada en una de las galerías de la subestructura conservada bajo el Carmen del Zenete, en la galería 3 (Fig. 7, a-b). En concreto, formaba parte de un potente nivel de relleno, de aproximadamente $50 \mathrm{~cm}$ de espesor, datado en época tardoantigua, con una fecha ante quem del s. $\mathrm{v}$ d. C., y en el que eran muy numerosas las inclusiones cerámicas y de material constructivo como 
fragmentos de ladrillos, ímbrices, tegulae, así como restos de mármoles variados, algunos de ellos pertenecientes a molduras e inscripciones. La escultura apareció boca abajo y muy próxima a varios fragmentos de molduras en mármol, caídos sin mayor cuidado en este espacio subterráneo y quedando acopiados en el interior del mismo, que ya estaba en desuso y abandonado en la Tardoantigüedad (Román, 2005 y 2014). La riqueza y variedad del material constructivo hallado en el citado relleno nos lleva a plantear su más que probable procedencia del entorno más inmediato. Es posible que la pieza que estudiamos hubiera estado erigida en el cerca-

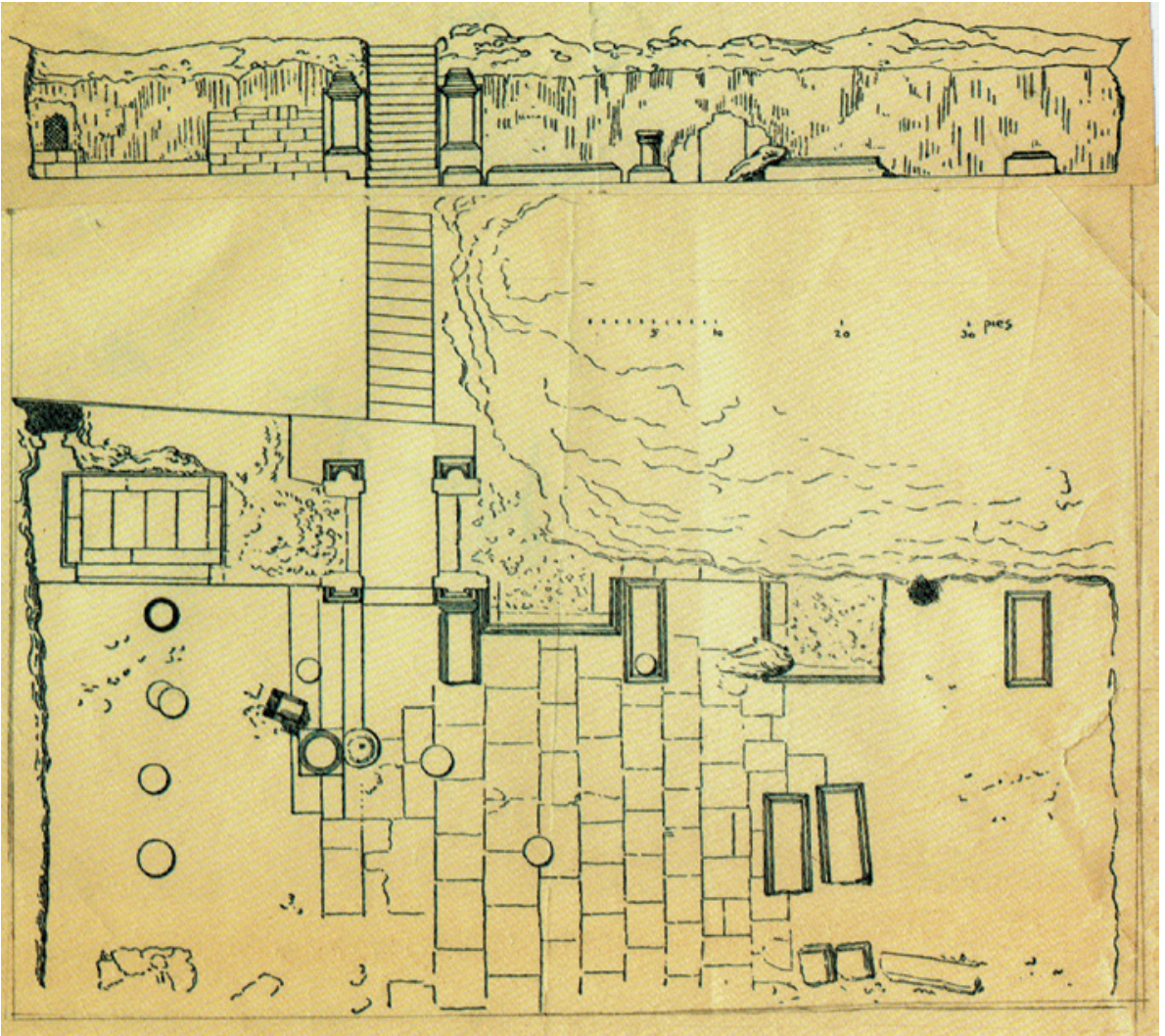

Fig. 2. Plano y alzado de los restos del foro de Florentia Iliberritana hallados por Juan de Flores en el Albaicin de Granada; dibujo de Diego Sánchez Sarabia en 1769, depositado en la Fundación Rodríguez-Acosta de Granada (según Orfila, 2008: 187). no foro cívico de Floren-

tia Iliberritana (Fig. 1), el cual estaría siendo objeto en este momento tardío de un evidente proceso de desmantelamiento, lo que se testimoniaría además por la presencia de los otros elementos marmóreos.

\section{Estudio del retrato}

\subsection{Descripción formal y estilo}

La cabeza que estudiamos (Fig. 8 a-d) está trabajada en un solo bloque y presenta unas dimensiones de $30 \mathrm{~cm}$ de altura conservada, por un ancho máximo de $20 \mathrm{~cm}$, por lo que su tamaño resulta algo mayor que el natural. Conservada actualmente en el Museo Arqueológico de Granada, ha sido esculpida en mármol blanco muy fino que presenta una pátina rojo-amarillenta y restos de suciedad en superficie. No hemos podido determinar aún su procedencia, a la espera realizar análisis petrográficos. Su estado de conservación no es bueno y presenta algunas roturas: la oreja izquierda ha perdido parte del lóbulo y de la hélix (Fig. 9a), así como el pabellón auditivo en la derecha (Fig. 9b), y tiene además algunos desperfectos en la nariz. Presenta asimismo desgaste en la barba, sobre todo en la parte frontal, y en el cabello; no obstante, la superficie del retrato muestra un fino pulimento original en las zonas carnosas en las que lo ha conservado, como en parte de las mejillas, labios y ojos.

Corresponde a un retrato y se ha representado a un hombre con barba y de rasgos maduros. En la parte frontal, el peinado se estructura en dos hileras de ondas que se extienden sobre la frente y las sienes 
en dirección contraria, la superior con las puntas hacia su derecha, mientras que la inferior hacia la izquierda. El flequillo forma una onda de gran volumen, que se extiende sobre la frente y las sienes, de oreja a oreja. El peinado adquiere forma de casquete, ante la falta de naturalidad en la elaboración de los mechones, lo que se acentúa por la existencia de un resalte o escalón que diferencia el borde del flequillo de la frente y de las mejillas, y que se advierte asimismo en la zona del cuello, en ambos laterales y en la nuca. La frente se estrecha enormemente hasta quedar constreńida a una estrecha franja que ocupan en parte las cejas. Dispone de unos prominentes arcos supraciliares que cobijan unos ojos más grandes de lo habitual, delimitados en la parte superior con profundos surcos; los párpados están bien esculpidos y los lacrimales marcados con un toque de trépano. Por el contrario, en el interior del

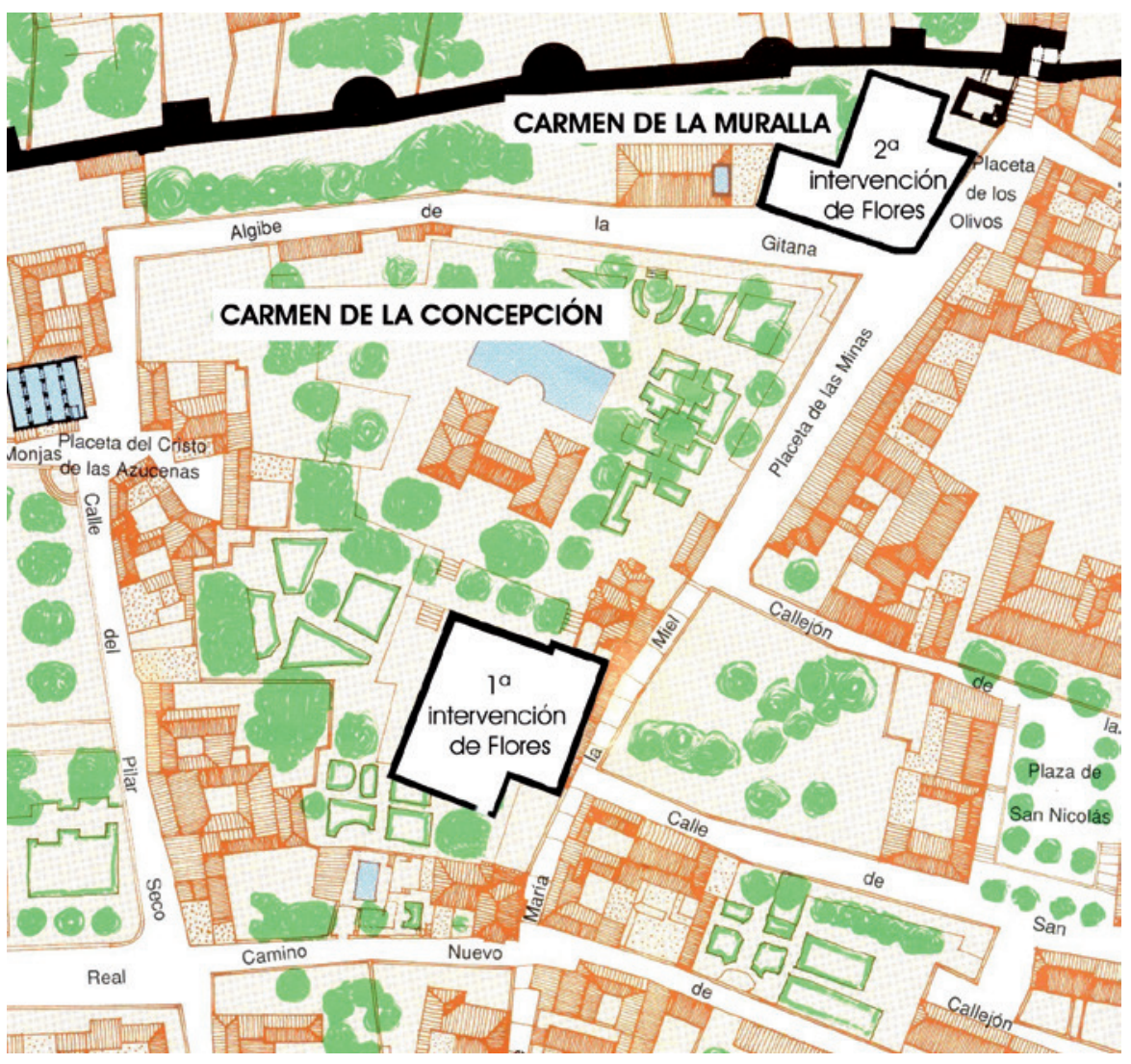

Fig. 3. Localización de las excavaciones de J. de Flores, del s. XVIII, en el actual Carmen de la Concepción, en el Albaicin de Granada (Sotomayor y Orfila, 2006: fig. 1). ojo no se han señalado el iris y la pupila. En la parte inferior de los párpados se aprecian unas pequeñas bolsas, así como unas leves líneas horizontales en sus extremos, signos evidentes de la edad del retratado. En la parte posterior el cabello se distribuye en forma de estrella a partir de un hipotético punto central, a la altura de la coronilla; a partir de ella los mechones se han tallado en forma de hélice con las puntas dirigidas hacia su derecha, que se reparten en una serie de líneas ordenadas en función de su longitud y con las puntas contrapuestas. Los mechones que se dirigen hacia el frente son más largos, en forma de gran 's' y se sitúan por encima de la segunda hilera antes mencionada, conformando un singular perfil escalonado, con cuatro 'escalones' desde la coronilla al flequillo. Por el contrario, los mechones que caen hacia atrás desde la coronilla están menos desarrollados y se completan con otras tres filas de mechones más cortos, que se distribuyen regularmente sobre la nuca y en ambos laterales del cuello; la superior e inferior curvan los extremos de los mechones a la izquierda y la central a la derecha. Además, se advierte como en el lateral izquierdo los rizos inferiores se curvan hacia arriba inmediatamente detrás de la oreja, aunque han sufrido alguna pérdida (Fig. 9a-b). Ambas orejas también han sufrido deterioro en los pabellones auditivos, pero aún se advierte que un surco separaba el lóbulo en ambos casos.

La nariz es grande y prominente, aunque su impacto sobre el rostro está atenuado en la actualidad por la rotura 


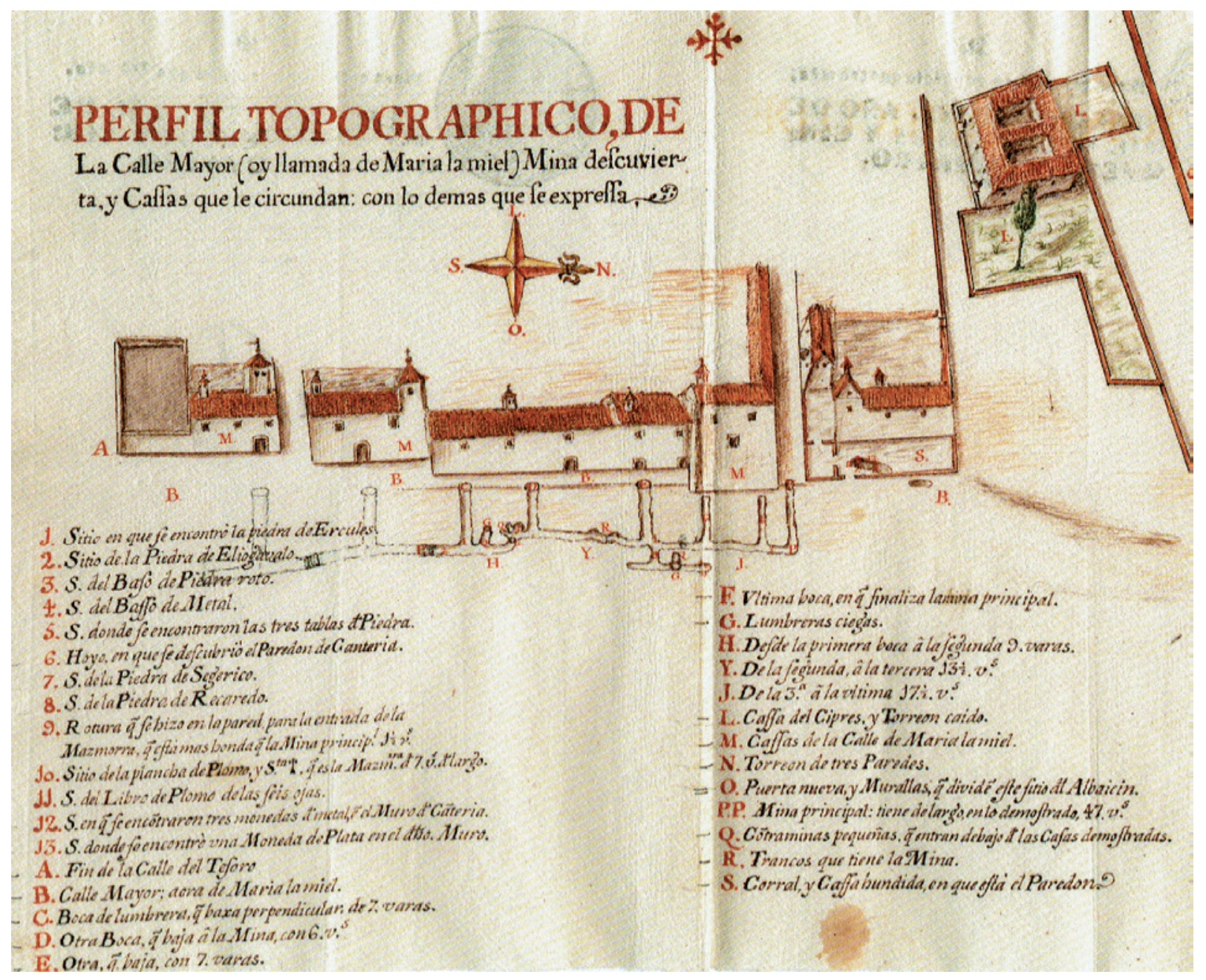

FIG. 4. Dibujo encargado por Flores en 1754 del "perfil topográfico" de la calle María la Miel, con indicación de las casas, las galerías subterráneas ("mina") y los pozos de entrada o aireación. Colección particular, Granada (Orfila, 2008: 171).

que afecta a la mayor parte de la misma. En la base superior se aprecian dos líneas paralelas, dos leves arrugas. Una poblada barba se extiende en la parte inferior de la cara, cubriendo el mentón y el inicio del cuello; es en las mejillas donde parece más densa, estructurada en varias líneas superpuestas de rizos. La barba ha sido trabajado con el trépano, un uso que se hace más evidente en la parte derecha y en la parte inferior del cuello, mientras que en la izquierda el trabajo con este instrumento es más escaso. El taladro ha servido para marcar el centro de los rizos de la frondosa barba. Se trata de una técnica que está bien documentada desde época flavia en adelante para rizos del peinado en retratos de particulares (Cain, 1993: 219-222, n. ${ }^{\text {os }} 93$ y 94 ). La boca está casi oculta por la barba, que se une a un frondoso bigote de largas guías, de forma que llegan casi a confundirse. La boca es de labios finos, que aparecen cerrados; el superior está casi oculto bajo el bigote, mientras que el inferior se muestra bien delineado y de su parte inferior arranca la barba. Se han marcado bien los pliegues nasolabiales. La cabeza está ligeramente girada hacia su izquierda y no podemos saber si correspondió a un busto o a una estatua completa; es posible que esto segundo fuera más conveniente, si formó parte del programa 
estatuario del foro municipal iliberritano, aunque ello no es determinante. No conserva restos de vestimenta en la parte del cuello que se ha conservado. En la oreja derecha tiene un pequeño agujero circular realizado con trépano o taladro, que debió servir para una introducir una espiga metálica, cuya función desconocemos (Fig. 9a).

\subsection{Análisis iconográfico y paralelos}

\subsubsection{Paralelos en bulto redondo}

La estructura del cabello en la parte frontal de la cabeza recuerda en principio a un tipo de peinado usado por el emperador Nerón, mediante coma in gradus formata, con una forma particular de distribución del cabello sobre la frente a modo de cresta, que en ocasiones se asocia a una incipiente barba o barbula (Bergmann y Zanker, 1981: 322-326; Born y Stemmer, 1996: 55-56, láms. 23 y 24). Ese tipo de peinado será asimismo puesto de moda de nuevo por el emperador Domiciano (Cain, 1993: 102; Bergmann, 1998: 147-149; Borg, 1998: 159).
Finalmente, serán los retratos del emperador Adriano los que retomen esta particular forma de peinado de coma in gradus, aunque con una serie de variantes que lo diferencian de forma clara de sus antecesores, sobre todo en lo que respecta al flequillo, con sus característicos rizos (Evers, 1994). A ello habría que sumar el uso de la barba tupida, que pone de moda este emperador y que se vincula de manera directa con la cultura y la filosofía griegas tan apreciadas por el monarca (Zanker, 1995: 190-206; Borg, 2008: 158-160). Esos elementos se transmiten al retrato privado, dentro de una clara influencia del retrato imperial, que determina el desarrollo de la retratística particular desde el retrato oficial; aunque asimismo hay otras tendencias de ritratti non-assimilati, como ha destacado Klaus Fittschen en un esclarecedor estudio, analizando precisamente la variedad de retratos masculinos privados en el período adrianeo (Fittschen, 1992-1993). La asimilación por parte de particulares en época adrianea de aquel peinado de coma in gradus se puede observar en tres retratos; uno de la Gliptoteca de Munich, de excelente calidad, con el iris y pupila horadados, que quizás fuera el retrato del amicus Hadriani, Titus

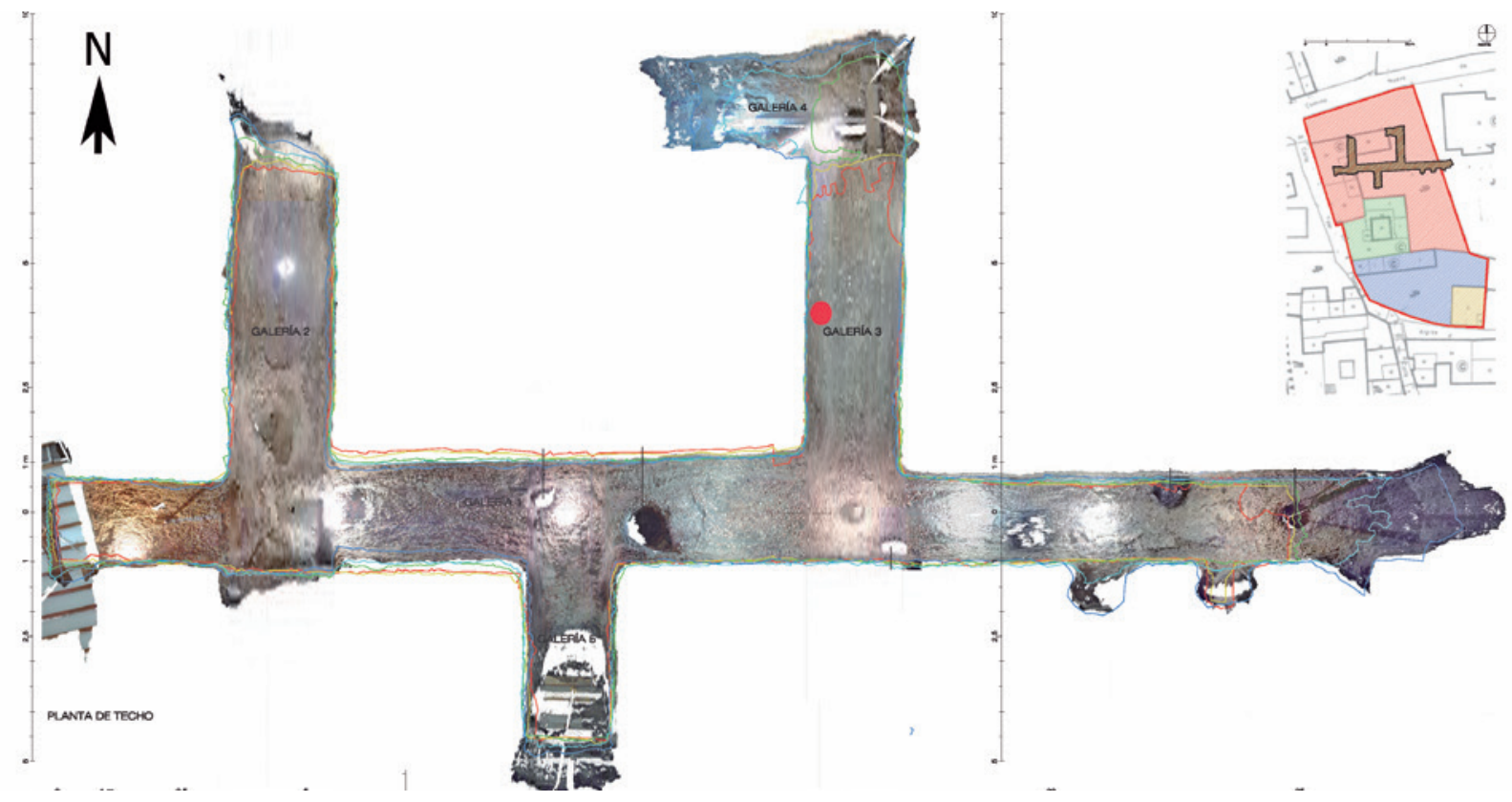

Fig. 5. Planta general del complejo de galerías excavadas en 2017-2018 en el Carmen del Zenete, con la ubicación (punto en rojo) del hallazgo de la escultura (BIMnD e I. Quemada Arquitectos). 
Caesernius Statianus (Fittschen, 1992-1993: 460, fig. $\left.4, n .{ }^{\text {os }} 1-2\right)$; otro de un particular conservado en los Museos Capitolinos (n. ${ }^{\circ}$ inv. 430), procedente de la antigua colección Albani, sin el iris y la pupila trabajados, y sin barba (Fig. 10a-b) (Fittschen, 1992-1993: 460, fig. 11, n.o 3; Fittschen, Zanker y Cain, 2010: 74-76, n. ${ }^{\circ}$ 69); y un tercero de otro particular conservado en el Louvre (n. ${ }^{\circ}$ inv. MA 1215; cit. en Fittschen, Zanker y Cain, 2010: 75, n. $\left.{ }^{\circ} 2\right)$. Se relacionan estos ejemplares con el retrato del emperador Adriano del tipo delle ciocche arrotolate, indicando K. Fittschen que es evidente “... che il prototipo per le due repliche è almeno stato usato ancora sotto Adriano, se non fu appunto una creazione del suo tempo..." (Fittschen, 1992-1993: 460, n. 43). Llamamos la atención sobre la pieza de los $\mathrm{Mu}-$ seos Capitolinos porque presenta una disposición del flequillo muy similar a la del retrato granadino que estudiamos, con los mechones dirigidos hacia la izquierda de manera repetitiva y monótona, de oreja a oreja en forma curva y destacados por un reborde en la frente y sienes, así como contrapuestos a los de la fila superior; todo ello le da ese aspecto característico del tocado en forma de casquete.

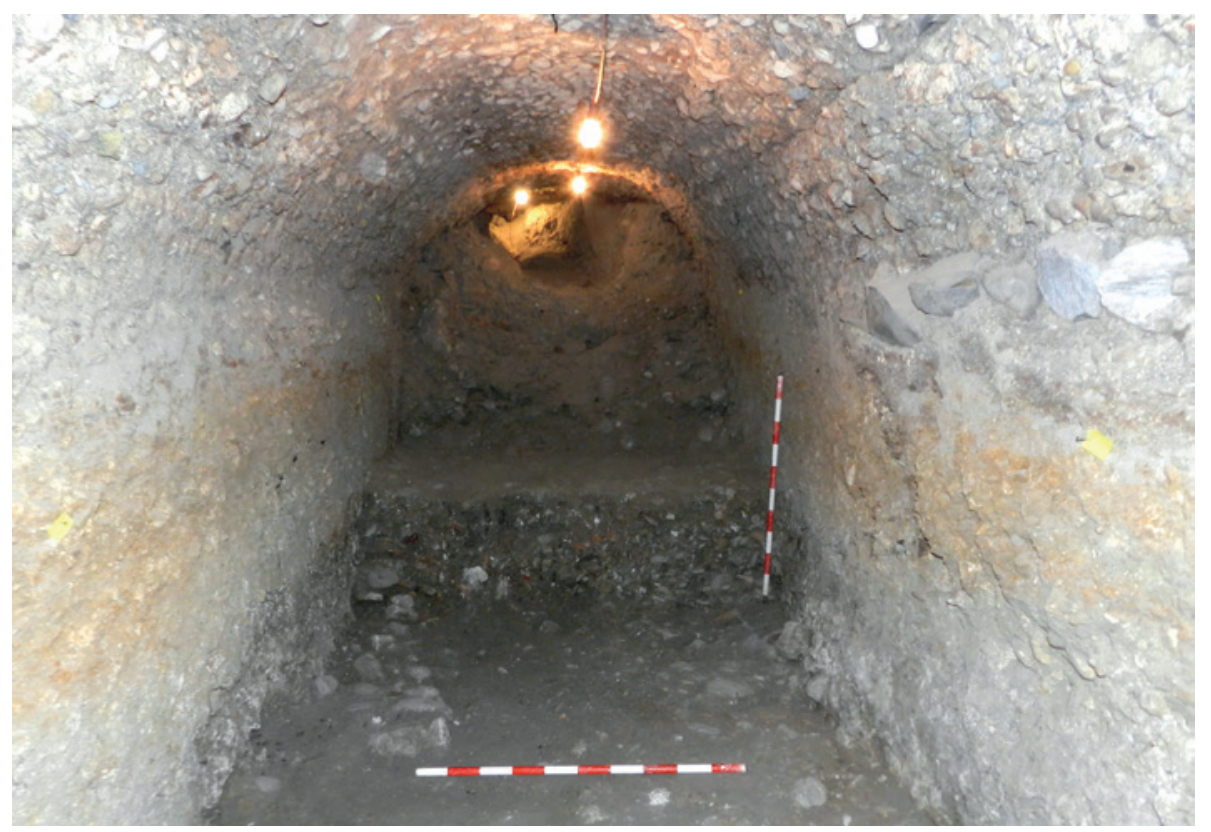

Fig. 6. Detalle de la galería 3 del Carmen del Zenete (Granada).
También podemos hacer referencia a otro retrato conservado en la Galleria degli Uffizi de Florencia (Fittschen y Zanker, 1985: 44, n.o 46, láms. 49-51; Fittschen, 1992-1993: 450, fig. 2, n.o 3), de época tardoadrianea, que sí presenta barba; aunque el resto del peinado sigue el retrato de Adriano tipo Stazione Termini-de hecho, fue considerado anteriormente como retrato del emperador-, de nuevo la disposición de los mechones del flequillo, dirigidos los extremos hacia la izquierda y dejando una frente estrecha, lo aparta del retrato imperial y lo caracteriza como retrato de particular. Se relaciona asimismo con el retrato que analizamos, aunque la calidad de ejecución y el naturalismo claroscurista son mucho mayores que en los casos de los ejemplares de Granada y de los Museos Capitolinos. También podemos llamar la atención sobre otro ejemplar de la misma cronología que el granadino, entre 120 y 130 d. C., aunque es una estatua completa de un particular representado como Hércules (Fig. 11), conservado en el Museo de El Prado, con una frente estrecha en la que "las puntas de los rizos [del flequillo] forman una línea horizontal sobre la frente y en algunos casos se tocan unas con otras, tal como también ocurre en el primer tipo de retrato del emperador Adriano, de 117 d. C." (Schröder, 1993: 186, n.o 51). En este caso asimismo la barba, más apuntada, se articula a base de rizos que disponen en algunos casos puntos de trépano en su centro, si bien todo el conjunto es de un mayor naturalismo y calidad que la pieza granadina.

En otro sentido, también podemos traer a colación un retrato marmóreo en bulto redondo conservado en el $\mathrm{Mu}$ seo Nacional Romano (n. ${ }^{\circ}$ inv. 565431), que 

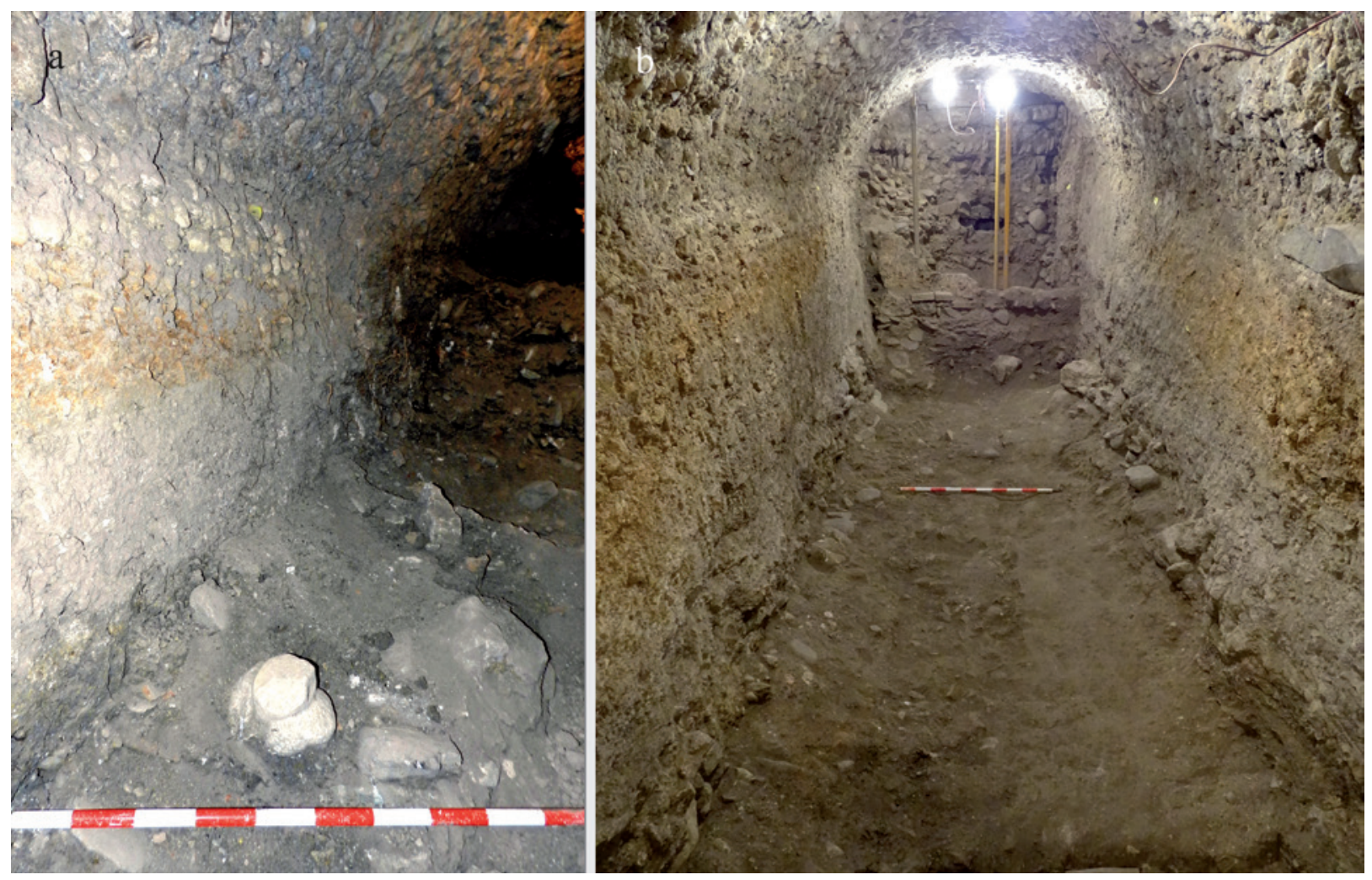

Fig. 7. Lugar de hallazgo del retrato romano: A) detalle del descubrimiento y B) la galería tras su excavación.

apareció en las recientes excavaciones de la villa de via Anagnina, en Roma, y que se ha datado en época trajanea (Friggeri, Magnani Cianetti y Carusso, 2014: 96-97, n. ${ }^{\circ}$ 16). En este caso el flequillo responde mejor a la iconografía imperial trajanea, derivado del tipo Decennalia, con los mechones sobre la frente en forma de amplias eses con los extremos dirigidos hacia la izquierda, pero es coincidente con el ejemplar iliberritano en la frente estrecha y el reborde citado del cabello, estando presente ya la barba, aunque no tan desarrollada como en el caso granadino. Características similares ofrece el retrato de un oficial romano, con un collar, datado en época tardotrajanea, que presenta " ... mechones escalonados de curvatura paralela, peinado que sigue en uso de forma similar aún en tiempos de Adriano..." (Schröder, 1993: 164), constituyendo un reborde sobre la frente, aunque la barba, cerrada, corresponde mejor a momentos trajaneos; incluso podríamos llevar su datación a época adrianea temprana, dentro de los ejemplares que imitan aún el peinado de Trajano. Precisamente K. Fittschen sitúa en ese momento un retrato fragmentario conservado en Toronto, de época tardoadrianea, que sigue el tipo trajaneo Louvre MA 1250, aunque su estilo es más naturalista y de mejor calidad (Fittschen, 1992-1993: 460, fig. 12, n. ${ }^{\text {os }} 1-2$ ). Ello enlazaría con otra serie de ejemplares recopilados por el mismo Fittschen en los que, apareciendo barbados, se advierte aún la influencia del peinado trajaneo en época adrianea, constituyendo en cierto modo ejemplos de "certi tipi fisionomici (cioè di tipi non-individuali)... una delle particolarità dell'arte ritrattistica adrianea" (Fittschen, 1992-1993: 482, y figs. 28, n. $\left.{ }^{\text {os }} 1-4\right)$. En ese mismo apartado incluye la famosa estatua considerada tradicionalmente como de Juliano el Apóstata, del Museo del Louvre, pero que sería de un particular de "época adrianea, anzi, a causa della mancanza dell'incisione degli occhi, nella prima età adrianea... rappresentante de quel genere 

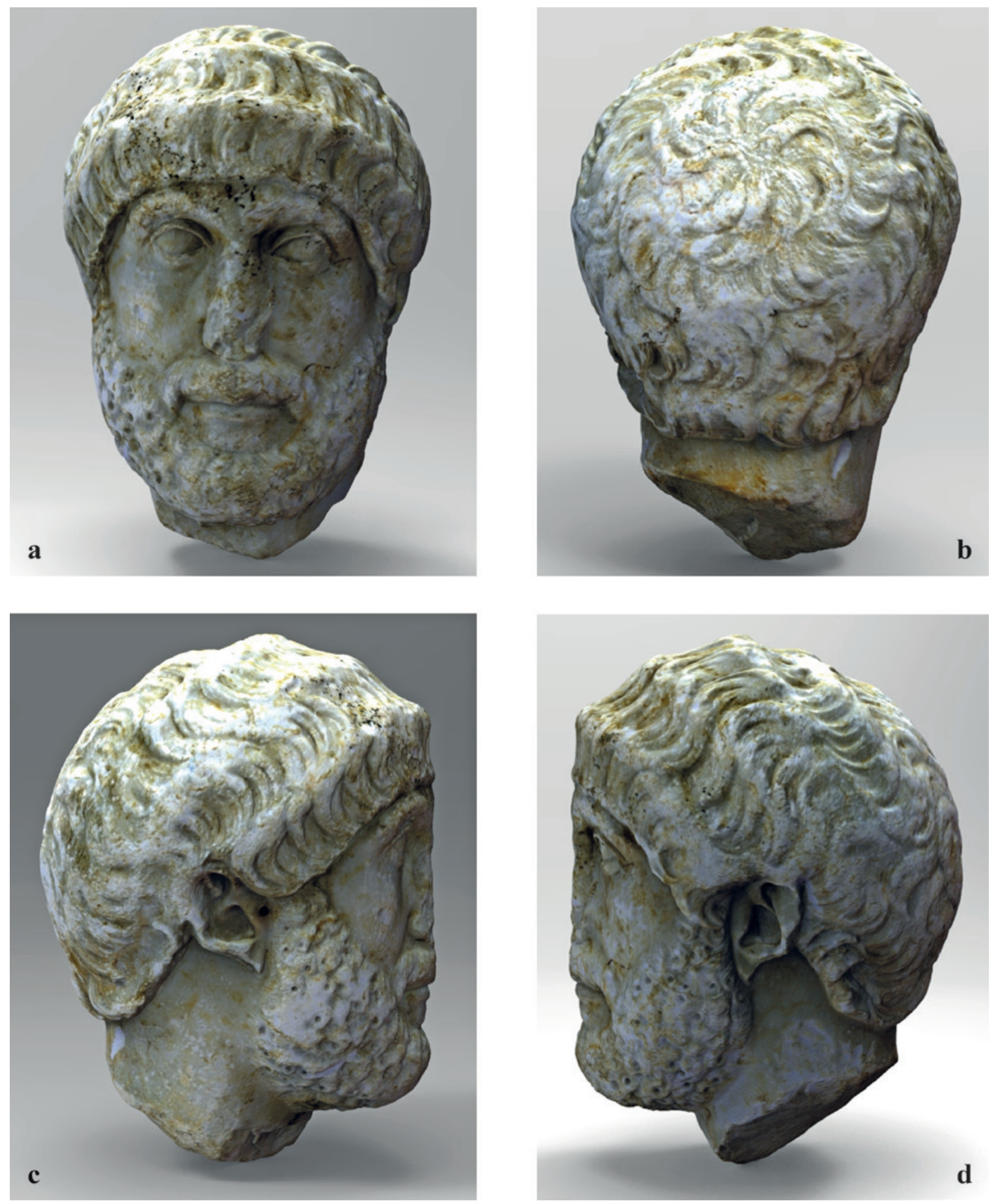

FIG. 8. Diversas perspectivas del retrato masculino procedente de las excavaciones del Carmen del Zenete, hoy depositado en el Museo Arqueológico de Granada: a) frontal. b) posterior; c) lateral derecho; d) lateral izquierdo $(0,30 \times 0,20 \mathrm{~m})$. 

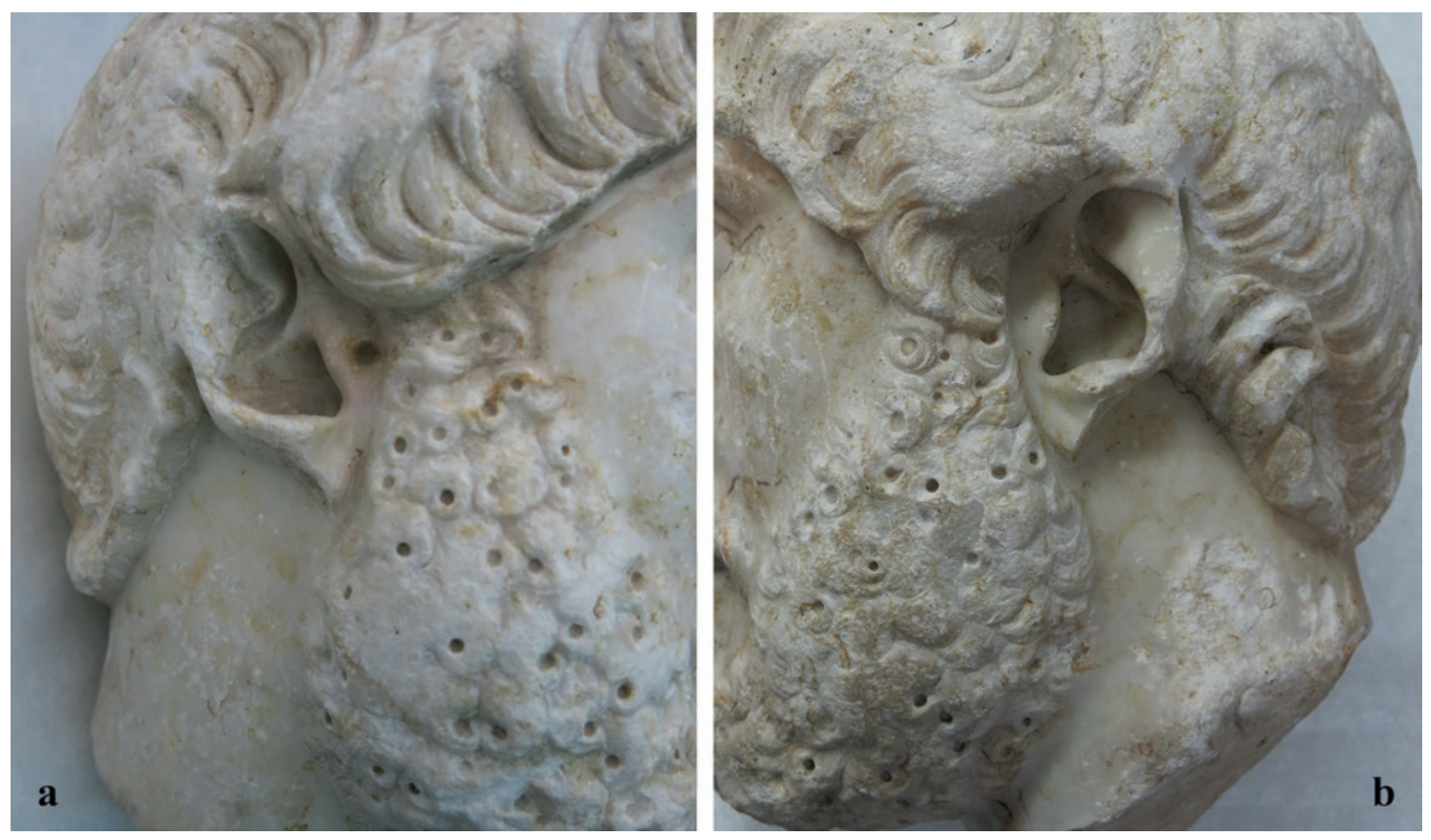

FIG. 9. Detalle de la cabeza: a) lateral derecho del retrato; b) lateral izquierdo.

di ritratti poco assimilati a quelli dell'imperatore regnante (inquesto caso solo in quanto alla barba), i quali continuano la tradizione traianea, combinadola con una forte tipizzazione" (Fittschen, 1992-1993: 485).

\subsubsection{Paralelos en relieves}

No obstante, los paralelos más fidedignos para nuestro retrato se encuentran en el campo del relieve. En primer lugar, podemos mencionar el singular relieve en mármol procedente de Praeneste, que representa un triunfo y que se expone en el Museo Arqueológico Nacional de Palestrina -n. ${ }^{\circ}$ inv. 6520-; corresponde a un bloque de mármol de Luni, de $1,7 \mathrm{~m}$ de altura $\mathrm{x} 1,17 \mathrm{~m}$ de anchura $\mathrm{x} 0,37 / 0,40$ $\mathrm{m}$ de grosor (Fig. 12a). Frente a su datación tardorromana, como se pensó en el momento de su descubrimiento en 1967 , se trataría de una representación imperial de Trajano celebrando el triunfo pártico tras su muerte y consecratio (Musso, 1987). Según ha concluido Musso (2008: 143; 2017) debe de corresponder, en efecto, a "la pompa trionfale del rilievo del divus Traiano, collegata con la definitiva sistemazione delle sue ceneri, come eccezionale ceremonia sostitutiva dei funerali di Stato di un altrettanto eccezionale imperatore cui il Senato, all'indomani deIla noticia della sua morte, aveva già attributo divini honores". El bloque está incompleto por su lado derecho y, en lo conservado, representa al emperador en la cuadriga, coronado por un servus publicus y precedido por ocho lictores que llevan las fasces, sin los secures, mientras otros dos se sitúan junto al carro, cuyos caballos son conducidos por otros dos servi; cierra el conjunto -en la parte superior derecha, por encima de otros dos personajes de los que solo se han representado las cabezas en un relieve más bajo- un trofeo con un escudo pártico, alusivo a las victoriosas campañas trajaneas contra los partos.

No queda claro como continuaba el relieve en el otro bloque colocado a la derecha, aunque posiblemente solo se debió completar esa escena, si se considera que el cáliz de acanto que se sitúa en la parte superior y del que brotan a ambos lados los 
zarcillos acantiformes con animales ocupaba el centro de la composición. Tampoco quedan claras la función y localización del relieve, que se ha querido vincular a la decoración de una puerta o, más bien, de un altar, o del pedestal de un monumento conmemorativo erigido en Praeneste, pero siguiendo un posible modelo oficial de Roma, según defienden Musso (2008: 143) y Ojeda (2011: 69-70, n. $\left.{ }^{\circ} 51\right)$. Agnoli (2000 y 2002: 222-234, n. ${ }^{\circ}$ III.5) relacionó el relieve con la inscripción CIL XIV, 2933, que recoge parte del cursus honorum del cónsul Quintus Fabius Postuminus, praefectus Urbi a fines del reinado de Trajano e importante personaje de la corte trajanea; considera que el relieve decoraría su tumba en Praeneste, aunque fuera excepcional que se representara el triunfo imperial en un contexto privado. Se ha afirmado también que realmente el personaje de la cuadriga sería el propio Postuminus, con una corona etrusca (Bergmann, 2010: 89-91), pero ese extremo no parece adecuado si tenemos en cuenta que se trata de una corona que alude a la divinización del personaje principal que ocupa el carro y a que su fisonomía sigue el modelo de Trajano, por lo que sería representación de divus Traianus Parthicus, como reafirma Musso (2017).

Lo que más nos interesa del relieve son los retratos de algunos de los lictores (Agnoli, 2002: 225; Musso, 2008: 142). Así, centramos nuestra atención en el retrato del segundo lictor de la fila inferior, más cercano a la cuadriga triunfal, que presenta -casi de frente, con un leve giro a su izquierda- dos filas de mechones sobre la frente y hasta las orejas, con los extremos del flequillo vueltos hacia la izquierda y contrapuestos a los de la fila superior, dejando libres las orejas (Fig. 12b). La frente es muy estrecha bajo el flequillo y dispone de una barba poblada y rizada. Parece evidente la similitud tipológica con el retrato de Granada, a pesar del formato en que se ha ejecutado. A su derecha, por delante de él, se ha representado otro lictor más joven, imberbe, pero
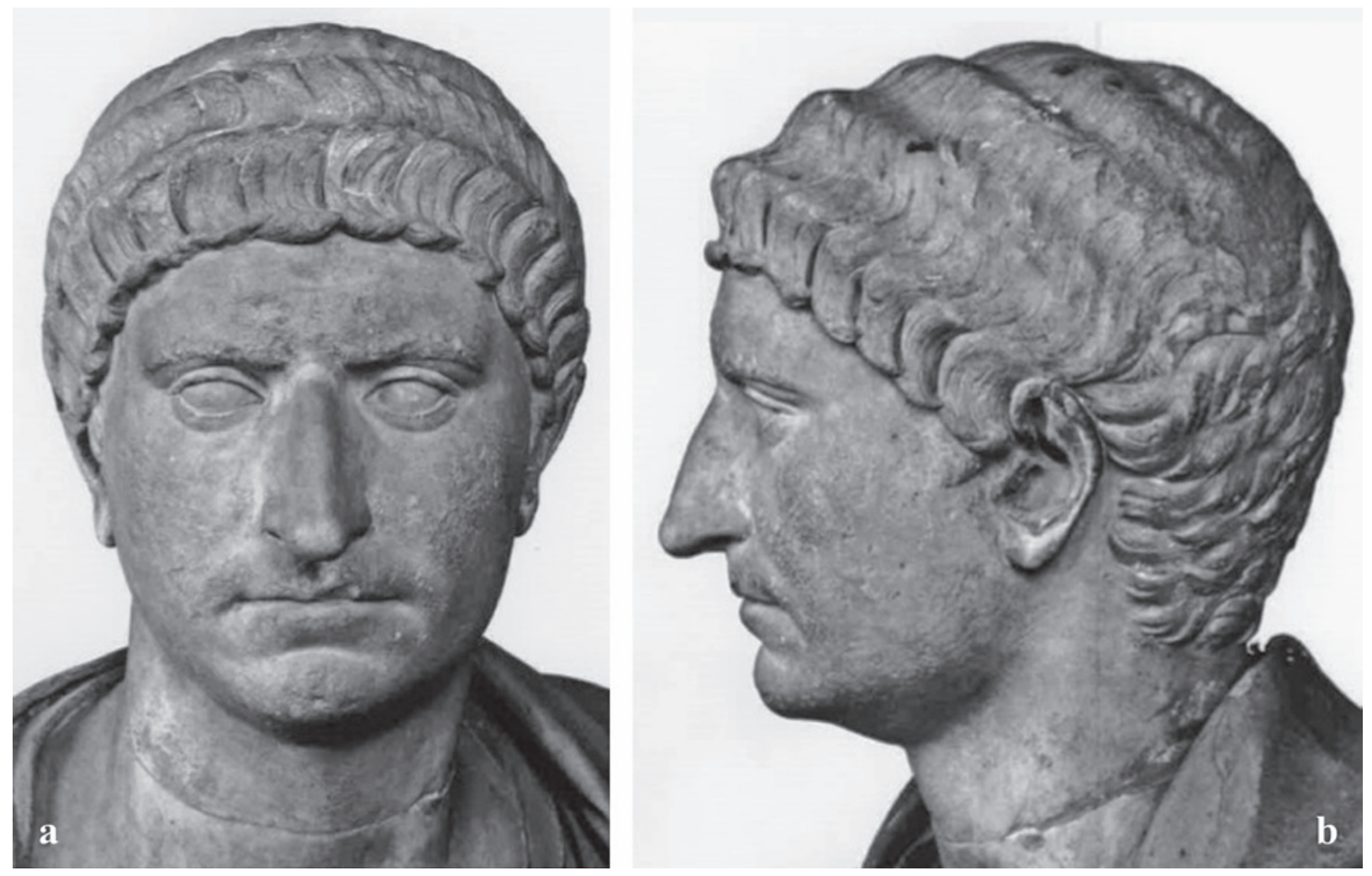

Fig. 10. Retrato masculino: a) vista frontal; b) lateral izquierdo. Museos Capitolinos, Roma (Fittschen et al., 2010: n. ${ }^{\circ}$ 69). 


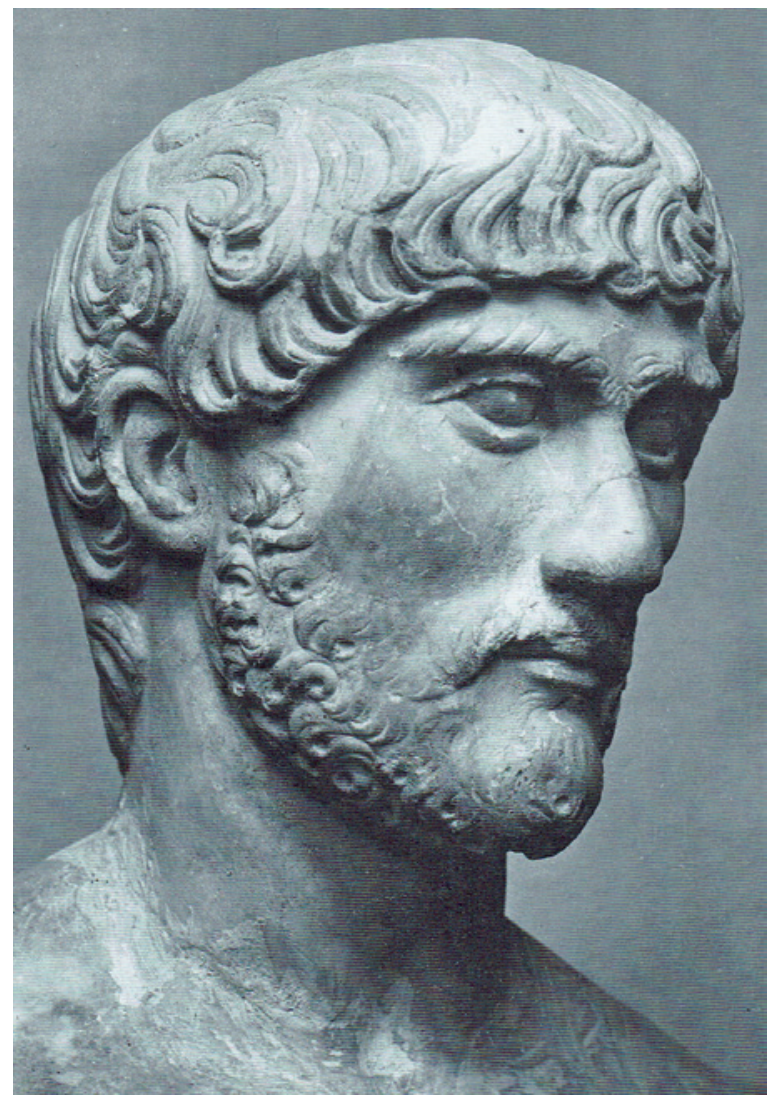

FIG. 11. Detalle del retrato de un particular como Hércules. Museo del Prado (Schröder, 1993: n. ${ }^{\circ}$ 51).

con el cabello dispuesto de manera similar (Agnoli, 2002: 233), rememorando el modelo de coma in gradus, aunque los mechones en este caso parecen más similares a los del propio divus Traianus representado en la cuadriga. El siguiente lictor situado a su derecha, de tres cuartos, asimismo imberbe, dispone los cabellos de una manera más fiel al retrato trajaneo, con largos mechones que caen sobre la frente, como asimismo otro de los dos lictores que se sitúan junto al carro; corresponderían también a la tendencia, sobre todo en los primeros momentos del reinado de Adriano, de mantener el tipo de peinado propio de Trajano. Por el contrario, algún otro lictor-como el situado más a la izquierda en la fila superior (buena reproducción en Agnoli, 2002: 231) - presenta barba y flequillo con rizos acaracolados, más próximo al modelo de peinado de Adriano. Es el retrato del lictor primero al que nos hemos referido el que presenta el mejor paralelo para la pieza de Granada, por la forma de la barba y, sobre todo, por la disposición 'escalonada' del cabello, con el típico peinado que esquematiza y simplifica la coma in gradus; además, presenta la singularidad de que es el único que porta una torques en su cuello. Se ha dicho que estos retratos diversos de los acompañantes del emperador divinizado eran simples retratos tipificados, que no respondían a personajes concretos (Agnoli, 2002); en el caso del lictor que hemos destacado, con la presencia de la torques, podría hacer referencia genérica a un occidental, por ejemplo, un celta, galo o incluso hispano, pero incluso también a un personaje concreto, conocido, dentro de los lictores que acompañaban al emperador en vida, dada la singularidad del retrato. Como argumenta Schröder (1993: 164), “... a principios del siglo II d. C. los galos y los celtas aparecen con el adorno tradicional en el cuello tan sólo en las copias de obras helenísticas", haciendo referencia además a la torques de oro, "como las que Augusto (Suetonio, Aug. 43) y Tiberio, entre otros, concedían en contadas ocasiones a personalidades de alto rango". Quizás ello redunda en el hecho de que aquel lictor pudiera ser identificado de manera concreta entre el séquito imperial trajaneo, siendo, quizás, de origen hispano.

En segundo lugar, podemos aducir el conocido altar funerario de Titus Statilius Aper, muerto con 22 años, 8 meses y 15 días, y de su mujer Orcivia Anthis (Fig. 13), que fue dedicado por sus padres T. Statilius Proculus y Argentaria Eutychia, y que se conserva en los Museos Capitolinos (La Rocca y Parisi Presicce, 2010: 'seconda sala terrrena destra, n. $\left.{ }^{\circ} 5^{\prime}\right)$. La estatua togada del difunto, que era mensor aedificorum, aparece esculpida en el frente del cuerpo central; sobresale el retrato: con barba tupida y rizada, en la que los rizos se han marcado con golpes de trépano, y cabello dispuesto en filas 'escalonadas' de mechones, que en el flequillo disponen los extremos hacia la izquierda; en este caso se ha simplificado la diferencia entre las filas escalonadas y los mechones del flequillo aparecen más separados entre sí, con profundos surcos entre ellos, mientras la frente no es tan reducida. A pesar de 
todo, es un buen paralelo para el retrato granadino, estando datada la elaboración del altar en el reinado de Adriano.

\subsection{Relación con el retrato de Adriano: el modelo imperial}

En conclusión, el retrato de Granada debía representar a un particular cuya elaboración fue llevada a cabo en época adrianea, por la presencia de la barba y el tipo de peinado ya analizado, en una fecha anterior al ańo $130 \mathrm{~d}$. C., en que se pone de moda en el retrato romano que iris y pupila se reexcaven, lo que no aparece en nuestra pieza. Algunos autores consideran que ese hecho se produjo a partir de la muerte del favorito Antínoo (Wegner, 1956: 87-88; Meyer, 1991). Otro rasgo que apunta a la vinculación de la pieza granadina con la plástica adrianea es el pulimento que presenta la superficie de la cara en las zonas donde lo ha conservado, además de la ausencia de detalles fisionómicos que hagan evidente la edad, como bolsas situadas bajo los ojos, pliegues labionasales marcados o las arrugas en la frente o sobre la nariz; ello va acorde con el retrato de Adriano, que ofrecía una apariencia atemporal y el paso de la edad solo se hacía evidente en ciertos detalles menores (Evers, 1994: 238). Además, hay que añadir otro rasgo característico, como es la hendidura o muesca oblicua que presentan los retratos del emperador en los lóbulos de las orejas, que está presente en todas las imágenes de Adriano a partir del tipo Delta Omikron, usado en su juventud, antes de ser investido como emperador (Schröder, 1993: 190; Bergmann, 1997: 142-143; Söldner, 2010: 222-224); se trataría de una singuralidad fisionómica que se asocia con la predisposición a sufrir algún tipo de patología cardíaca (Birley, 2005: 302, nota 6). Algunos retratos de particulares de época adrianea asimismo imitan esa característica del emperador, como ocurre en el ejemplar granadino que estudiamos, a pesar de las roturas que presentan ambas orejas.

La barba se asemeja también en la forma a la del propio emperador, como se advierte en la disposición redondeada del perfil o en como el vello nace desde debajo mismo del labio inferior, aunque en la barba del emperador no se utiliza el trépano para marcar el centro de los rizos; una excepción lo constituye un retrato de Adriano en Ostia,
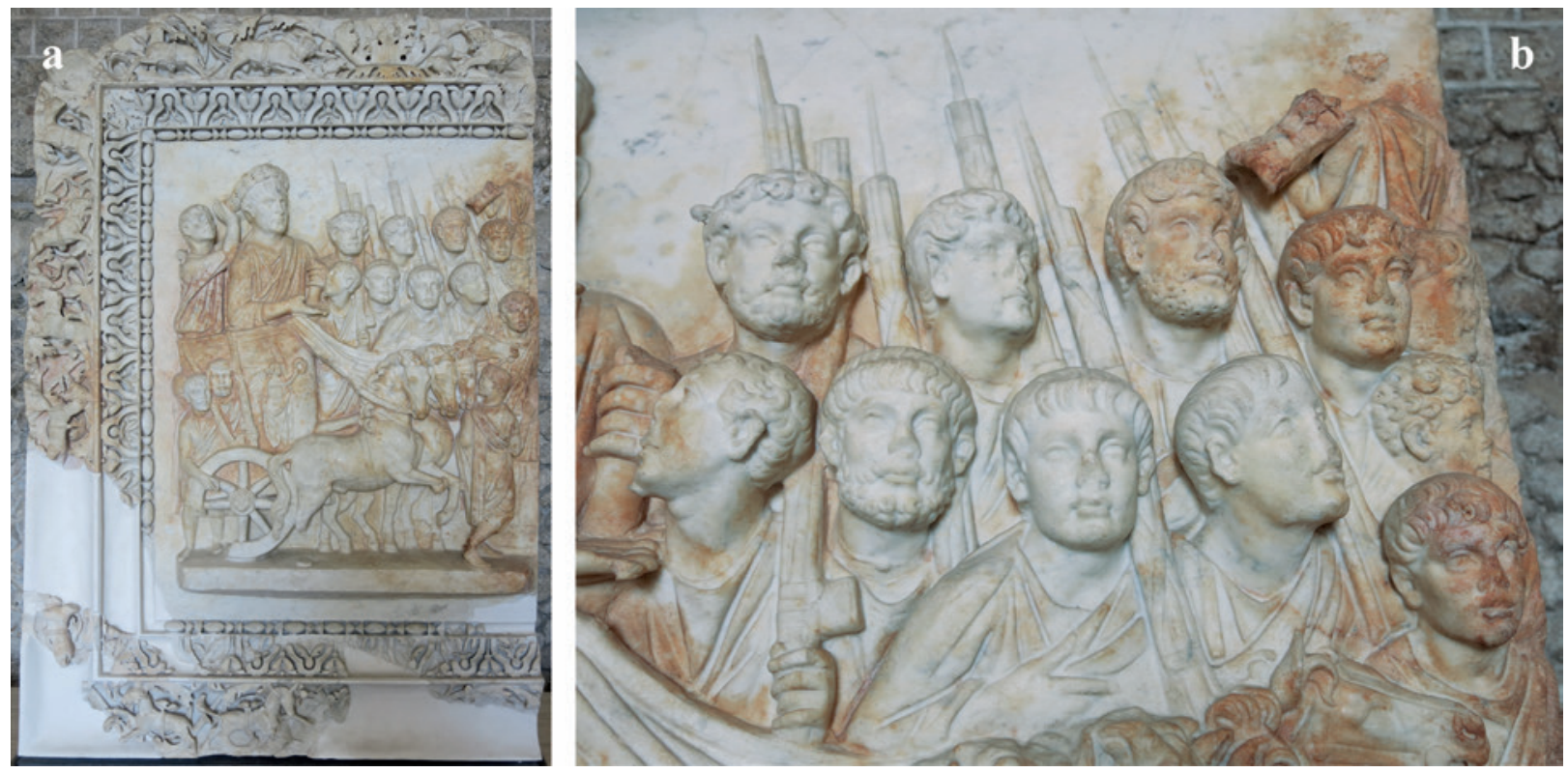

Fig. 12. Relieve de la pompa triunfal del Divus Traianus $(1,7 \times 1,17 \times 0,37 / 0,40 \mathrm{~m})$ en el Museo Arqueológico Nacional de Palestrina: a) vista general y b) detalle. 
conservado en el Museo Ostiense (Evers, 1994: 143, n. ${ }^{\circ} 78$, lám. III, 14). También es similar el estilo del bigote. Por el contrario, es muy diversa la forma de la cabeza, que es más estrecha en nuestro caso que en la del emperador, que aparece casi redondeada en su vista frontal, a lo que ayuda la forma del tocado imperial tan elaborado. La disposición de los cabellos en el frente de la cabeza granadina no se relaciona de manera directa con ninguno de los tipos de Adriano (Bernoulli, 1891; Wegner, 1956; Fittschen, 1984; Fittschen y Zanker, 1985; Evers, 1994; Bergmann, 1997), pero sí es similar en algunos casos en la disposición escalonada de las filas de mechones que van desde la coronilla hacia adelante. Entre otros ejemplos, se puede observar en el busto de Adriano de fines del reinado encontrado en el foro de Italica (León, 1995: 8081, n. ${ }^{\circ}$ 22), que presenta varios 'escalones' desde la coronilla hasta terminar en el flequillo con los habituales rizos del Rollockenfrisurtypus, con los extremos vueltos hacia la izquierda

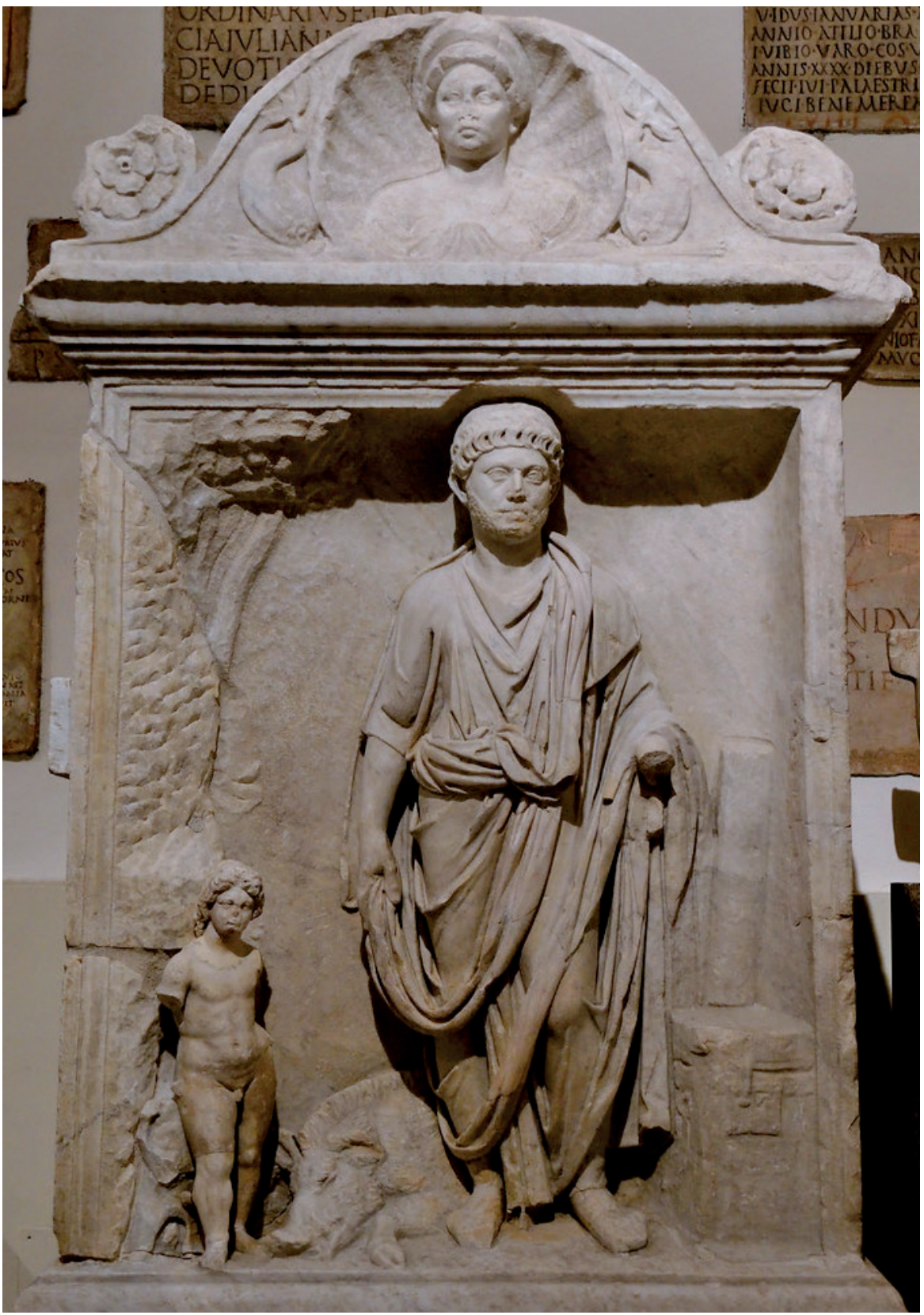

FIG. 13. Altar funerario de Titus Statilius Aper. Museos Capitolinos, Roma. (Evers, 1994: 233-240).

Tampoco es fácil encontrar un modelo claro en la retratística adrianea si nos fijamos en la parte posterior del peinado del retrato granadino; a partir del motivo estrellado de rizos que ocupa la coronilla se disponen tres líneas de cortos mechones escalonados, las dos superiores con las puntas hacia la izquierda y la tercera contrapuestos a partir de una pinza abierta en la parte derecha. Solo encontramos cierta similitud con el esquema de otro de los tipos establecidos para el retrato de Adriano por 


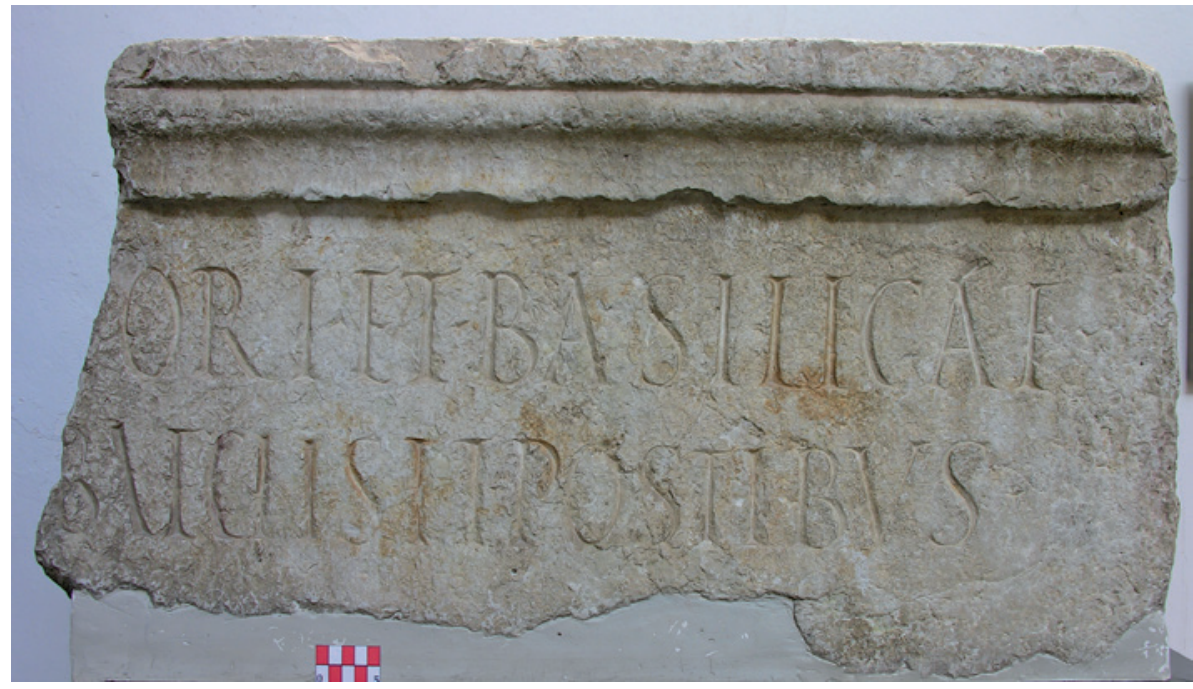

FIG. 14. Inscripción CIL II2/5: n. 634 depositada en el Museo Arqueológico de Granada (Orfila, 2008: 190).

K. Fitschen (1984), el llamado 'Tipo Tarragona', precisamente por un retrato procedente de Tarraco (Koppel, 1985: 94-95, n. ${ }^{\circ}$ 126) y conservado en el Museo Nacional Arqueológico de Tarragona (n.o inv. 389). Para Cécile Evers (1994: 240-245) es difícil discernir entre los tipos Rollockenfrisur y Tarragona, considerando que, más que un tipo nuevo, el de Tarragona podría ser solo una variante del anterior; a los cuatro ejemplares recopilados por Fittschen (1984) -el de Tarraco, un segundo hispano (procedente de la villa de Borriol y conservado en Castellón de la Plana; Arasa, 2000: 156-157), y otros dos de Italia, conservados en el Museo de los Conservadores y en Hovingham Hall, respectivamente- une otros dos, uno de Esparta y otro de Italia (Evers, 1994: 240-241).

Hemos de destacar el singular conjunto de rizos que se situaba por detrás de las orejas y que formaba una especie de tirabuzón, pero que se ha conservado parcialmente, sobre todo en el lado izquierdo (Fig. 9b). Precisamente ese detalle iconográfico solo se da en el retrato de Adriano en algunos ejemplares, especialmente también en esos pocos que se engloban bajo el tipo Tarragona. Por ciertos detalles como el pronunciado pliegue nasolabial, Fittschen dató el 'Tipo Tarragona' en época tardoadrianea (Fittschen y Zanker, 1985: 58), pero Evers lo sitúa en la primera mitad del reinado de Adriano, entre el 119125 d. C., junto a los primeros ejemplos del tipo Rollockenfrisur (Evers, 1994: 244-245), y -teniendo en cuenta que el ejemplar tarraconense es el cabeza de serie, de taller local, posiblemente ubicado en la capital provincial- vinculó incluso su creación a la estancia de Adriano en Tarraco en los años 122-123 d. C. (González-Conde, 2019: 40-47). Ello podría justificar asimismo el que dos de los seis ejemplares testimoniados procedan de Hispania, incluyendo el que da nombre a la serie, de la capital provincial tarraconense. Además, habría que agregar ahora otro tercer ejemplar que, conservado en el Palacio de Viana, en Córdoba, se ha dicho que debe de proceder de algún territorio de la actual provincia cordobesa, quizás de Hornachuelos (Garriguet, 2018). No sabemos la procedencia del mármol utilizado en el retrato de Granada, al que tampoco se le han hecho aún análisis petrográficos, pero de visu no parece que se ha utilizado un mármol de procedencia hispana. Es por ello que no podemos decantarnos sobre si la pieza fue de importación o elaborada en un taller hispano; caben argumentos en uno $\mathrm{u}$ otro sentido, pero ninguno determinante. Por un lado, se integra dentro de un conjunto heterogéneo de retratos que se documentan en lugares extrahispanos, especialmente en Roma, desde fines del reinado de Trajano y, sobre todo, durante el de Adriano, así como la calidad del retrato original; pero, por otro lado, se vincula al tipo Tarragona del retrato de Adriano, que tiene una especial relación con territorios hispanos, en concreto de la Tarraconense y Bética (Tarragona, Borriol, ¿Hornachuelos?). 


\section{Valoraciones finales}

El representado se trataría de un personaje importante en Florentia Iliberritana, aunque no podemos saber si era de origen iliberritano o incluso hispano. Es probable, dado el contexto de descubrimiento, que durante la primera parte del reinado de Adriano se le erigiera este retrato -seguramente una estatua- en el foro municipal, si bien su carrera pública debería haberse desarrollado sobre todo bajo el reinado de Trajano, ya que se trata de un retrato de edad avanzada. Según se dijo, el foro florentino estuvo situado junto a la c/ María la Miel y zonas aledañas, donde hoy se encuentra el Carmen de la Concepción, en el que se han situado las excavaciones de Flores del s. XVIII (Figs. 1 y 3) (Sotomayor y Orfila, 2004 y 2011); contamos, además, con dos epígrafes de esa zona, grabados en sendos arquitrabes, en los que un séviro augustal, del que solo se conoce el cognomen Perseus, declara que costeó de su dinero la ornamentación de los intercolumnios del foro y de la basílica con rejas, jambas y puertas, durante la segunda mitad del s. II d. C. ( $\mathrm{CIL} \mathrm{II}^{2} / 5,633$ y 634), lo que refrenda que aquellos restos eran realmente parte del foro municipal (Fig. 14). La vinculación del retratado con la corte de Adriano pudo tener lugar en los años 122-123 d. C., cuando el emperador estuvo viviendo en la ciudad de Tarraco, en la que restauró el antiguo templo de culto imperial dedicado a Augusto durante el reinado de Tiberio, según se recuerda en las monedas (por ejemplo, Beltrán, 2012); asimismo, convocó una asamblea de representantes de las principales ciudades hispanas (González-Conde, 2019: 44-46), a la que pudo asistir -hipotéticamente- nuestro retratado. Pero su importancia pudo ser no solo a nivel local, provincial o hispana, sino tambien del imperio, y ser exponente de uno de los béticos que con Trajano y Adriano se elevaron hasta lo más alto en el escalafón social y político del imperio (González-Conde, 2019: 187-226). Es algo que no podemos discernir sin otra documentación.

De procedencia iliberritana conocemos especialmente tres familias de rango consular, la de los Cornelii, los Valerii y los Papirii, que, aunque trasladados a la capital al incorporarse al Senado, nunca perdieron su vinculación con la patria ni con la provincia, al menos durante el s. II d. C. (Pastor, 2004; Jiménez, 2008). Así, es ejemplo de las propiedades que estas familias granadinas conservaban en la Bética la creación -seguramente en época de Marco Aurelio y que se mantenía aún en época de los Severos- de la procuratela centenaria del Kalendarium Vegetianum para la administración de las propiedades donadas al emperador por un Valerius Vegetus (Sáez y Lomas, 1981; Remesal, 1996). Del foro florentino se han recuperado algunos pedestales que se refieren a miembros de estas familias, como los cónsules Publius Cornellius Anullinus (CIL $\mathrm{II}^{2} / 5$, 623); Vegetus -antecedente del anterior- (CIL II²/5, 627); Gnaeus Papirius Aelianus (CIL II $2 / 5$ : n. ${ }^{\circ}$ 626); así como a la madre de Vegetus, Cornelia Severina, que fue flaminica en el municipio ( $\mathrm{CIL} \mathrm{II}^{2} / 5$ : n. ${ }^{\circ}$ 624), y a su mujer Etrilia Afra ( $\left.\mathrm{CIL} \mathrm{II}^{2} / 5,625\right)$, quizás procedente de la colonia de Tucci, en Martos (Pastor, 2004: 39, n. 78). También otra reciente inscripción grabada sobre un pedestal nos documenta la erección de una estatua a un patronus del municipio, de época altoimperial, pero del que se desconoce el nombre por rotura del soporte (Orfila, 2008: 192). A un rango menor podemos citar las inscripciones dedicadas seguramente en pedestales también localizados en el foro a magistrados locales, duoviros y ediles, como a Lucius Galerius Valerianus (CIL II $2 / 5,630)$, Silvinus Fabius ( $\mathrm{CIL} \mathrm{II}^{2} / 5,632$ ) y Quintus Valerius (Pastor, 2004: 57-59, n. ${ }^{\circ} 24$ ), además de a la sacerdos Patricia (CIL $\mathrm{II}^{2} / 5,631$ ) o al exmilitar Quintus Cornelius (CIL II $2 / 5,629)$.

No se han conservado en el ámbito forense de Florentia Iliberritana dedicaciones a emperadores de los ss. I-II d. C., aunque lógicamente debieron de existir las dedicadas a Trajano y Adriano, por la preponderancia que tuvieron en Hispania y, sobre todo, en su provincia de origen (González-Conde, 2019: 114-152). Solo nos han llegado tres pedestales dedicados a algunos emperadores o miembros de sus familias del s. III d. C. recuperados en ese entorno forense iliberritano. Así, uno de una estatua 
de Furia Sabina Tranquilina, esposa del emperador Gordiano III ( $\left.\mathrm{CIL} \mathrm{II}^{2} / 5,620\right)$, hoy perdido; otro incompleto, pero que no puede ser posterior al 267 d. C. (Pastor, 2002: 32-33, n. ${ }^{\circ}$ 5, fig. 2 a-b; Pastor, 2004, 117-125, n.o 2); finalmente, el dedicado al emperador Probo ( $\mathrm{CIL} \mathrm{II}^{2} / 5,622$ ), tampoco conservado en la actualidad. Los tres fueron descubiertos en las proximidades del llamado Aljibe del Rey, edificio que dista unos $100 \mathrm{~m}$ del lugar de hallazgo del retrato iliberritano, certificando su procedencia forense. Los descubrimientos escultóricos realizados en este sector forense no han sido muy importantes; aparte de dos estatuas femeninas vestidas fragmentadas, destacan la parte inferior de una escultura con dos pies masculinos desnudos, junto al inicio del soporte lateral, de dimensiones mayores al natural, que debía corresponder a una estatua de divinidad o, en todo caso, de un emperador divinizado; y un fragmento de un togado, que se ha datado en la primera mitad del s. I d. C. (Moreno, 2008 y 2010).

El foro de Florentia Iliberritana sería una construcción aterrazada, adaptada a la orografía del terreno y localizado a escasos $60 \mathrm{~m}$ al $\mathrm{N}$ de nuestra subestructura, en lo que actualmente es el n. ${ }^{0} 11$ de la c/ María la Miel y parte de los jardines del Carmen de la Concepción (Orfila, 2011: 91 y 94). Las numerosas evidencias arqueológicas, tanto epigráficas, escultóricas, elementos constructivos, así como restos estructurales aparecidos desde época moderna y hasta el presente en este entorno -Aljibe del Rey, Carmen de la Muralla, Huerto Lopera y c/ María la Miel-, no dejan lugar a dudas de que en esta parte de la ladera meridional del cerro se localiza el foro. Tanto la citada subestructura como el gran edificio hallados en c/ Gumiel n. ${ }^{\text {os }} 4$ y 6 , solo pueden entenderse en el contexto forense en el que nos hallamos, los cuales se ubicarían topográficamente en una zona más baja y al s de donde se extendería la plaza pavimentada del foro descubierta por Juan de Flores en el s. XviIr. En el interior de uno de los pasillos abovedados que conforma la citada estructura subterránea fue donde se halló el retrato, amortizado en un depósito arqueológico conformado en una fecha tardoantigua, y que se sella durante el s. v d. C. Se plantea por tanto la hipótesis de que la estatua de la que formaría parte fue erigida en ese foro florentino durante la primera parte del reinado del emperador Adriano, con anterioridad a $130 \mathrm{~d}$. C.

\section{Bibliografía}

Agnoli, N. (2000): "Il rilievo con la raffigurazione del trionfo di Traiano e l'iscrizione di Q. Fabius Postuminus", Xenia Antica, Ix, pp. 21-46.

Agnoli, N. (2002): Museo Archeologico Nazionale di Palestrina. Le sculture. Roma.

Arasa Gil, F. (2000): "Esculturas romanas de la provincia de Castellón”. En León, P. y Nogales, T. (eds.): Actas de la III Reunión sobre Escultura romana en Hispania. Madrid, pp. 149-171.

Barrios, M. y Pastor, M. (2017 ed. rev.[1781]): "Introducción". En Razón del Juicio seguido contra los falsificadores de la Alcazaba del Albaicín de Granada. Granada.

Beltrán Fortes, J. (2012): "L'origen del culte imperial a Hispània i el seu reflex en les emissions romano provincials". En Cамpo, M. (ed.), Déus i mites de la antiguitat. L'evidència de la moneda d'Hispània, Barcelona, pp. 277-298.

Bergmann, M. (1997): "Zu den Porträts des Trajan und Hadrian”. En Caballos, A. y León, P. (eds.): Italica MMCC. Actas de las Jornadas del 2200 Aniversario de la Fundación de Italica. Sevilla, pp. 137-154.

Bergmann, B. (2010): Der Kranz des Kaisers. Genese und Bedeutung einer römischen Insignie. Göttingen.

Bergmann, M. y Zanker, P. (1981): "Damnatio memoriae. Umgearbeitete Nero und Domitians Porträts. Zur Ikonographie der flavischen Kaiser und des Nerva", Jahrbuch des Deutschen Archäologischen Instituts, 96, pp. 317-412.

Bernoulli, J. J. (1891): Römische Ikonographie II, 2. Die Bildnisse der römischen Kaiser und ihren Angehörigen. Von Galba bis Commodus. Stuttgart.

Birley, A. R. (2005): Hadrien. London-New York.

Borg, B. (2008): Paideia: The World of Second Sophistic. Berlin-New York.

Born, H. y Stemmer, K. (1996): Damnatio Memoriae. Das Berliner Nero-Porträt. Mainz am Rhein.

CAIn, P. (1993): Männer Bildnisse neronisch-flavischer Zeit. München. 
CIL II'/5 (1998): Corpus Inscriptionum Latinarun. Inscriptiones Hispaniae. Editio altera. Fasc. v. Conventus Astigitanus. Berlin.

Evers, C. (1994): Les portraits d'Hadrien. Typologie et ateliers. Bruxelles.

FitTschen, K. (1984): "Eine Büste des Kaisers Hadrian aus Milreu in Portugal. Zum Problem von Bildnisklitterungen”, Madrider Mitteilungen, 25, pp. 197-207.

FitTschen, K. (1992-1993): "Ritratti maschili privati di época adrianea. Problemi della loro varietà", Scienze dell'Antichità. Storia-Archeologia-Antropologia, 6-7, pp. 445-485.

Fittschen, K. y Zanker, P. (1985): Katalog der römischen Portraits in den Capitolinischen Museen und den anderen kommunalen Sammlungen der Stadt Rom. I, Kaiser- und Prinzenbildnisse. Mainz am Rhein.

Fittschen, K.; Zanker, P. y Cain, P. (2010): Katalog der römischen Portraits in den Capitolinischen Museen und den anderen kommunalen Sammlungen der Stadt Rom. II. Die männlichen Privatporträts. Mainz am Rhein

Friggeri, R.; Magnani, M. y Carusso, C. (eds.) (2014): Terme di Diocleziano: il chiostro piccolo della Certosa di Santa Maria degli Angeli. Milano.

Garriguet, J. A. (2018): "Un posible retrato de Adriano en el Palacio de Viana (Córdoba)". En Márquez, C. y OJEDA, D. (eds.): Escultura romana en Hispania VIII. Córdoba, pp. 579-595.

Gómez-Moreno, M. (1949): Misceláneas. Madrid, pp. 347-390.

González-Conde, M. P. (2019): Las provincias de Hispania en los años de Adriano. Madrid.

JiMÉNEZ JiMÉNEZ, M. (2008): "La sociedad romana iliberritana”. En Orfila, M. (ed.): Granada en época romana. Florentia Iliberritana. Granada, pp. 57-67.

La Rocca, E. y Parisi, C. (eds.) (2010): Musei Capitolini. Le Sculture. Palazzo Nuovo. Roma-Milano.

León Alonso, P. (1995): Esculturas de Itálica, Sevilla.

Meyer, M. (1991): Antinoos. Die archäologischen Denkmäler unter Einbeziehung des numismatischen und epigraphischen Materials sowie der literarischen Nachrichten. München.

Moreno, A. S. (2008): "Restos escultóricos de Florentia Iliberritana”. En Orfila, M. (ed.): Granada en época romana. Florentia Iliberritana. Granada, pp. 79-86.

Moreno, A. S. (2010): "Restos escultóricos procedentes de Florentia Iliberritana (Granada)". En Abascal, J. M. y Cebrián, R. (eds.): Escultura romana en Hispania VI. Murcia, pp. 219-237.
Musso, L. (1987): "Rilievo con pompa trionfale di Traiano al Museo di Palestrina”, Bollettino d'Arte, 72 (46), pp. 1-46.

Musso, L. (2008): "Rilievo con pompa trionfale di Traiano”. En La Rocca, E. y Tortorella, S. (eds.): Trionfi Romani. Milano, pp. 141-143.

Musso, L. (2017): "Triumphus funeri simillimus: il rilievo di Palestrina e il 'trionfo' postumo di Traiano". En Parisi, C.; Milella, M.; Pastor, S. y Ungaro, L. (eds.): Traiano. Costruire l'Impero, creare l'Europa. Roma, pp. 340-350.

OJeda, D. (2011): Trajano y Adriano. Tipología estatuaria. Sevilla.

Orfila, M. (ed.) (2008): Granada en época romana. Florentia Iliberritana. Granada.

Orfila, M. (ed.) (2011): Florentia Iliberritana. La ciudad de Granada en época romana. Granada.

Orfila, M. (2013): "Granada en época romana: los restos arqueológicos, una visión global”, Revista del Centro de Estudios Históricos de Granada y su Reino, 25, pp. 15-28.

Orfila, M. y Sánchez López, E. (2012): "Granada antigua a través de la arqueología. Iliberri-Florentia Iliberritana". En Beltrán, J. y Rodríguez, O. (eds.): Hispaniae Urbes. Investigaciones arqueológicas en ciudades históricas. Sevilla, pp. 475-526.

PAstor, M. (2002): Corpus de Inscripciones Latinas de Andalucía. Vol. Iv: Granada. Sevilla.

Pastor Muñoz, M. (2004): Sociedad y epigrafía en Granada en época romana. Granada.

Remesal, J. (1996): “Mummius Secundinus: el Kalendarium Vegetianum y las confiscaciones de Severo en la Bética (HA Severus 12-13)”, Gerión, 14, pp. 195-222.

Román, J. M. (2005): "Algunas consideraciones acerca de Eliberri en época tardoantigua”, Anales de Arqueología Cordobesa, 16, pp. 161-180.

Román, J. M. (2014): "Redescubriendo la Granada tardoantigua. Eliberri entre los siglos IV al viII d. C.", Cuadernos de Prehistoria y Arqueología de la Univ. de Granada, 24, pp. 497-533.

Román, J. M. (2017): "De cuando Granada fue una ciudad romana: visión desde la arqueología”, Alzada, 114, pp. 29-39.

SÁez, P. y Lomas, J. (1981): "El Kalendarium Vegetianum, la annona y el comercio del aceite", Mélanges de la Casa de Velázquez, 17, pp. 55-84.

Schröder, S. F. (1993): Museo del Prado. Catálogo de la Escultura Clásica. I. Los Retratos. Madrid.

SöLDNER, M. (2010): "Die Bildhauerkunst während der Regierungszeit des Hadrian (117-138 n. Chr.). 
Facetten reiche Bildnisse im kaiserlichen Umfeld". En Bol, P. C. (ed.): Die Geschichte der antiken Bildhauerkunst 4. Plastik der römischen Kaiserzeit bis zum Tode Hadrians. Mainz am Rhein, pp. 215-236.

Sotomayor, M. (2008): “¿Dónde estuvo Iliberri? Una larga y agitada controversia ya superada”. En ORFILA, M. (ed.): Granada en época romana: Florentia Iliberritana. Granada, pp. 23-32.

Sotomayor, M. y Orfila, M. (2004): "Un paso decisivo en el conocimiento de la Granada romana (Municipium Florentinum Iliberritanum)", Archivo Español de Arqueología, 77, pp. 73-89.
Sotomayor, M. y Orfila, M. (2006): “D. Juan de Flores y el Carmen de la Muralla en el Albaicín”, Florentia Iliberritana, 17, pp. 411-431.

Sotomayor, M. y Orfila, M. (2011): "El foro de la Granada romana. Planos, plantas, alzados y dibujos”, Cuadernos de Prehistoria y Arqueología de la Univ. de Granada, 21, pp. 349-403.

Wegner, M. (1956): Hadrian, Plotina, Marciana, Matidia, Sabina. Berlin.

Zanker, P. (1995): The Mask of Socrates: The Image of the Intellectual in Antiquity. Bekerkey-Los Angeles. 